\title{
Homologs of breast cancer genes in plants
}

\author{
Oliver Trapp, Katharina Seeliger and Holger Puchta*
}

Botanical Institute II, Karlsruhe Institute of Technology, Karlsruhe, Germany

\section{Edited by:}

Elena R. Alvarez-Buylla, Universidad Nacional Autónoma de Mexico, Mexico

\section{Reviewed by:}

Joseph F. Petolino, Dow AgroSciences, USA

Li-Zhi Gao, Kunming Institute of Botany, Chinese Academy of Sciences, China

\section{${ }^{*}$ Correspondence:}

Holger Puchta, Botanical Institute II, Karlsruhe Institute of Technology,

D-76128 Karlsruhe, Germany. e-mail: holger.puchta@kit.edu
Since the initial discovery of genes involved in hereditary breast cancer in humans, a vast wealth of information has been published. Breast cancer proteins were shown to work as tumor suppressors primarily through their involvement in DNA-damage repair. Surprisingly, homologs of these genes can be found in plant genomes, as well. Here, we want to give an overview of the identification and characterization of the biological roles of these proteins, in plants. In addition to the conservation of their function in DNA repair, new plant-specific characteristics have been revealed. BRCA1 is required for the efficient repair of double strand breaks (DSB) by homologous recombination in somatic cells of the model plant Arabidopsis thaliana. Bioinformatic analysis indicates that, whereas most homologs of key components of the different mammalian BRCA1 complexes are present in plant genomes, homologs of most factors involved in the recruitment of BRCA1 to the DSB cannot be identified. Thus, it is not clear at the moment whether differences exist between plants and animals at this important step. The most conserved region of BRCA1 and BARD1 homologs in plants is a PHD domain which is absent in mammals and which, in AtBARD1, might be involved in the transcriptional regulation of plant development. The presence of a plant-specific domain prompted us to reevaluate the current model for the evolution of BRCA1 homologs and to suggest a new hypothesis, in which we postulate that plant BRCA1 and BARD1 have one common predecessor that gained a PHD domain before duplication. Furthermore, work in Arabidopsis demonstrates that - as in animals - BRCA2 homologs are important for meiotic DNA recombination. Surprisingly, recent research has revealed that AtBRCA2 also has an important role in systemic acquired resistance. In Arabidopsis, BRCA2 is involved in the transcriptional regulation of pathogenesis-related (PR) genes via its interaction with the strand exchange protein RAD51.

Keywords: BRCA1, BRCA2, BARD1, BRCC36, breast cancer, DNA repair, homologous recombination, Arabidopsis

\section{INTRODUCTION}

All organisms must respond to naturally occurring DNA damage caused either by endogenous sources, such as reactive oxygen species, or exogenous sources, like UV radiation. Because of their sessile lifestyles, plants cannot avoid multiple exogenous stress factors. Moreover, plant germ cells are derived from undifferentiated meristematic cells. Because mutations resulting from inefficient DNA repair might be passed to the next generation, sophisticated DNA repair mechanisms are crucial for plant genomic integrity. During evolution, complex networks dealing with different kinds of DNA damage have developed in all organisms. Base excision repair, nucleotide excision repair and double strand break repair (DSBR) are the three most prominent examples. These mechanisms are conserved to different degrees throughout the different kingdoms of life. For DSBR, two main mechanisms to repair a double strand break (DSB) are used: homologous recombination (HR) and nonhomologous end joining (NHEJ). HR is the predominant mode of repair in bacteria and unicellular eukaryotes but is seldom used in multicellular diploid eukaryotes, which prefer NHEJ.

One of the most prominent factors involved in HR in mammals is the breast cancer susceptibility gene 1 (BRCA1), which was found while screening for genes involved in familial breast cancer in humans (Hall et al., 1990). In further screens for high-penetrance mutations leading to breast cancer, a second gene, $B R C A 2$, which is also involved in HR, was identified (Wooster et al., 1994, 1995). BRCA1 exhibits most of its functions in mammals in a heterodimer with the so-called BARD1 (BRCA1 associated RING domain protein 1) protein (Wu et al., 1996). The biological importance of BRCA1 and BRCA2 is clearly shown by the fact that progeny that carry a homozygous mutation in these genes exhibit embryonic lethality in mice (Hakem et al., 1996; Suzuki et al., 1997).

Breast cancer is the most common type of cancer among women in the western world, and approximately $5 \%$ of the cases have a hereditary cause. Mutations in the BRCA1 gene are responsible for $50 \%$ of these cases (Miki et al., 1994). Subsequently, women with a heterozygous BRCA1 mutation show an up to $80 \%$ higher probability of developing breast cancer throughout their lives. The cumulative risk of developing breast cancer for carriers of a $B R C A 2$ mutation approaches 50\% (O'donovan and Livingston, 2010). Hence, it is not surprising that much effort has been invested into elucidating the biological function of genes linked to breast cancer.

Recently, an almost uncountable number of studies have been published that shed light on the functions of HsBRCA1 and BRCA2, and it has become apparent that BRCA1 and BRCA2 are very diverse proteins with a huge number of interaction partners and many distinct functions. Besides their involvement in HR, HsBRCAl and BRCA2 are involved in cell cycle regulation, centrosome duplication, DNA repair, and transcriptional regulation (for a review of 
the cellular functions, see Boulton, 2006). For HsBRCA1, additional roles in the regulation of telomere length and in NHEJ have been described (Wei et al., 2008; Ballal et al., 2009).

BRCA2 (FANCD1) is also a member of the Fanconi anemia (FA) complex of proteins (reviewed in Wang, 2007; Kee and D'andrea, 2010). FA is a rare genetic disease in which patients have skeletal abnormalities and are prone to develop different kinds of cancer. Other BRCA1 and BRCA2 interacting proteins, e.g., FANCJ (BACH1) and PALB2 (FANCN), have also been linked to FA (Cantor and Xie, 2010; Tischkowitz and Xia, 2010), suggesting an intersection between breast cancer and FA.

It was quite a surprise to find a homolog of the human BRCA1 in seed plants. Interestingly, Arabidopsis plants with homozygous mutations in this gene show no developmental phenotype (Lafarge and Montane, 2003; Reidt et al., 2006). Two homologs of the human BRCA2 were identified in Arabidopsis, as well. Silencing both genes by RNA interference (RNAi) led to partially sterile plants, indicating an important role for BRCA2 in meiosis, but not in somatic growth (Siaud et al., 2004). The observation that Arabidopsis plants carrying homozygous BRCA1 or BRCA2 mutations develop to adult organisms instead of dying at a very early developmental stage, as is the case for mammals, offers a chance to study the function of these proteins during the complete life cycle of a multicellular eukaryote. In the following, we will summarize the current state of knowledge of the biological role of the respective homologs in plants.

\section{THE BRCA1 AND BARD1 PROTEINS}

The human BRCA1 protein has a length of 1863 aa and is comprised of an N-terminal RING (really interesting new gene) domain and two C-terminal BRCT (BRCA1 C-terminal) domains (Miki et al., 1994; Koonin et al., 1996; for schematic protein structure, see Figure 1).

The N-terminal RING domain was shown to exhibit E3 ubiquitin ligase activity, assembling unconventional K6-linked ubiquitin chains in humans; it is the site of interaction with BARD1 (Lorick et al., 1999; Meza et al., 1999; Wu-Baer et al., 2003). This

\begin{tabular}{|c|c|c|c|c|c|}
\hline HsBRCA1 & $\mathbb{W}$ & & E & $1863 a$ & \\
\hline AtBRCA1 & & 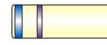 & WE & $941 \mathrm{a}$ & \\
\hline HsBARD1 & & 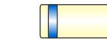 & IIDE & $777 a$ & \\
\hline AtBARD1 & & 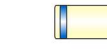 & Ela & $713 a$ & \\
\hline $\begin{array}{l}\text { RING } \\
\text { domain }\end{array}$ & \l $\begin{array}{l}\text { coiled-coil } \\
\text { domain }\end{array}$ & $\begin{array}{l}\text { Ankyrin } \\
\text { repeat }\end{array}$ & $\begin{array}{l}\text { extended PHD } \\
\text { domain }\end{array}$ & ] $\begin{array}{l}\text { core PHD } \\
\text { domain }\end{array}$ & $\begin{array}{l}\text { BRCT } \\
\text { domain }\end{array}$ \\
\hline \multicolumn{6}{|c|}{$\begin{array}{l}\text { FIGURE } 1 \text { | Structural comparison of the human and Arabidopsis BRCA1 } \\
\text { and BARD1. BRCA1 and BARD1 proteins of Homo sapiens and Arabidopsis } \\
\text { thaliana: Despite their difference in length ( } 1863 \text { aa in humans and } 941 \text { aa in } \\
\text { Arabidopsis), these proteins have a very similar composition with common } \\
\text { RING, P300/CBP interaction and BRCT domains. HsBRCA1 harbors a } \\
\text { coiled-coil domain that is absent in AtBRCA1, whereas we found a larger than } \\
\text { normal PHD in Arabidopsis BRCA1 and BARD1, but not in the human protein. } \\
\text { BRCT, BRCA1 C-terminal; CBP, CREB binding protein; P300, histone } \\
\text { acetyltransferase p300; PHD, plant homeodomain; RING, really interesting } \\
\text { new gene. }\end{array}$} \\
\hline
\end{tabular}

E3 ubiquitin ligase activity is amplified when BRCA1 and BARD1 interact (Hashizume et al., 2001). The heterodimer was shown to ubiquitinate itself and thus enhance its E3 ligase activity and its affinity to bind to DNA repair intermediates (Mallery et al., 2002; Simons et al., 2006). There have been several reports showing the ubiquitination of different substrates, such as RNA Polymerase II, in human cell lines (Starita et al., 2005). Furthermore, the ubiquitination of substrates, such as p53 and histones, has been described in vitro (reviewed in Starita and Parvin, 2006). The E3 ligase activity of the BRCA1-BARD1 heterodimer is also proposed to be regulated by the sumoylation of BRCA1 (Morris et al., 2009).

The two 80-100 aa long BRCT domains were shown to interact with phosphorylated proteins in humans. They can fold in a headto-tail manner and create an interaction pocket with high affinity to proteins that contain a phosphorylated serine in a pSer-X-X-Phe motif (Williams et al., 2001, 2004). Many proteins involved in DNA repair and cell cycle control harbor BRCT domains. The conservation of BRCT domains in many different organisms hints to an important and conserved function in these processes (Williams et al., 2004).

The human BRCA1 also contains a P300/CBP-interactiondomain that is thought to be involved in the regulation of transcription through an interaction with the transcriptional cofactors P300 (histone acetyltransferase p300) and CBP (CREB binding protein) (Scully et al., 1997a). Additionally, a coiled-coil domain was identified N-terminally of the BRCT domains of BRCA1 in humans. This domain is important for the transcriptional activation and is highly conserved throughout animals (Hu et al., 2000).

AtBRCA1 was first characterized and analyzed in a search for genes with the typical BRCA1 structure of an N-terminal RING and C-terminal BRCT domains in Arabidopsis (Lafarge and Montane, 2003). The AtBRCA1 protein is 941 aa long, weighs $104 \mathrm{kDa}$ and also harbors an N-terminal RING and two C-terminal BRCT domains. The AtBRCA1 and HsBRCA1 proteins show an overall identity of approximately $20 \%$ on the amino acid level that is higher in the described domains. All the important residues of the $\mathrm{C} 3 \mathrm{HC} 4$ amino acid motif in the RING domain are present in AtBRCA1, too. Thus, one might speculate that this domain exhibits E3-ligase activity like its human counterpart. Additionally, a conserved P300/CBP domain was found. A bioinformatics search revealed that no coiled-coil domain is present in Arabidopsis BRCA1.

A second ORF related to AtBRCA1 could be identified in the Arabidopsis genome and was classified as AtBARD1 (Reidt et al., 2006). Interestingly, the protein encoded by this gene lacks the Ankyrin (ANK) domains that are present in the human BARD1 protein but otherwise has a BRCA1/BARD1-like domain structure consisting of a RING and two BRCT domains. The ORF codes for a protein with a length of 713 aa. AtBARD1 has a 22\% identity and $38 \%$ similarity on the amino acid level to HsBARD 1 and $6.4 \%$ identity and 35\% similarity to AtBRCA1. With the split-YFP assay and the yeast two-hybrid ( $\mathrm{Y} 2 \mathrm{H})$ system, it was possible to show a direct interaction between AtBRCA1 and AtBARD1 (Reidt et al., 2006). It was demonstrated that the $\mathrm{N}$-terminus of AtBRCA1 can interact with the full-length AtBARD1, but not with the C-terminal part of AtBARD1. No interaction was found for the C-terminal fragments 
of AtBRCA1 and AtBARD1. Thus, AtBRCA1 and AtBARD1 seem to be able to interact via their N-terminal RING domains, much like BRCA1 and BARD1 in humans.

In the human BRCA1, there are two nuclear export signals (NES), which are located in the RING domain, and two nuclear localization signals (NLS), of which only the first one is vital for nuclear import (overview in Thompson, 2010). In Arabidopsis, the existence of NES and NLS and the localization of the protein is still unsure. The human BRCA1 and BARD1 were both shown to be located in the cytoplasm and the nucleus; transport between these two areas was shown to have a complex regulation. Nuclear import of HsBRCA1 can occur via the classical importin $\alpha / \beta$ pathway or in a piggyback mechanism with BARD1 (Chen et al., 1996; Fabbro et al., 2002). The retention of the heterodimer in the nucleus is accomplished by masking the NES when BRCA1 and BARD1 interact through their RING domains, where the two NESs are located. Thus, the exportins cannot bind to and transfer the proteins out of the nucleus. The localizations of AtBRCA1 and AtBARD1 have yet to be determined, but split-YFP assays have shown that the interacting heterodimer is localized in the nucleus (Reidt et al., 2006).

In Arabidopsis, an extended PHD domain (plant homeodomain) located between the P300/CBP and the BRCT domains (see Figure 1) can be identified by a SMART domain search (our own unpublished results). A PHD finger is similar to a RING finger but consists of a C4HC3 amino acid motif, instead of a C3HC4 motif, for binding a $\mathrm{Zn}^{2+}$ ion. PHD domains were previously shown to bind lysine 4 trimethylated histone $\mathrm{H} 3$ (H3K4me3), which can act as a dynamic signal for transcriptionally active genes and mark initiation sites for meiotic recombination (Santos-Rosa et al., 2002; Borde et al., 2009). This domain, which is approximately 60 aa long, was previously identified in AtBARD1 (Han and Zhu, 2009). An alignment between AtBRCA1 and AtBARD1 in the area of the PHD domains shows that not only is the classical PHD motif conserved but that a long stretch C-terminal of the PHD also shows high identity. This stretch ranges from 564 to 636 aa in AtBRCA1, where the classic C4HC3 motif of the PHD finger starts, and this highly conserved region ends at 688 aa. The identity between AtBRCA1 and AtBARD1 in this whole region is $53.2 \%$, showing that this region is even more conserved than the well-described RING and the two BRCT domains (52.6\% identity for RING, $47.1 \%$ for the first BRCT and $43.2 \%$ identity for the second BRCT domain; our own unpublished results). The fact that PHD fingers are mainly found in nuclear proteins suggests a nuclear localization for AtBRCA1 and AtBARD1 as well (Bienz, 2006).

The expression patterns of the plant proteins were checked in different organs. BRCA1 expression followed a gradient that rose from the rosette leaves up to the flower buds, with a 10 -fold higher BRCA1 expression in the latter (Lafarge and Montane, 2003). The expression of AtBARD1 was, like that of AtBRCA1, higher in flowers than in the rosette leaves. These similar expression patterns also hint at a functional interaction (Reidt et al., 2006). Another interesting experiment was conducted by screening for mRNA levels after irradiation with $\gamma$-rays. AtBRCA1 expression was highly induced by $\gamma$-rays with a 20-fold induction after irradiation with only 1-3 Gy. After irradiation with $100 \mathrm{~Gy}$, a maximum 800-fold induction was observed in rosette leaves, but only a 10 -fold increase was seen in flower buds, which equates to an average of 140 -fold induction of BRCA1 expression for the whole plant (Lafarge and Montane, 2003). Surprisingly, no induction of expression after $\gamma$-irradiation was measured for the BARD1 transcript (Reidt et al., 2006). This finding raises the question of why two proteins that usually act as a heterodimer are so differently expressed after genotoxic stress. Because the expression of both genes in mammals is induced similarly by $\gamma$-irradiation, there has to be a different regulatory mechanism for BRCA1 and BARD1 expression after DNA damage in plants.

\section{BRCA1 AND BARD1 IN OTHER PLANT SPECIES}

Apart from the BRCA1 and BARD1 homologs in Arabidopsis, we were able to find putative homologs bioinformatically in almost all sequenced plant genomes (our own unpublished results). We found at least one BRCA1 or BARD1 homolog in all the well established Viridiplanta genomes except for Physcomitrella patens. In all the examined Angiosperm genomes there are at least one BRCA1 and one BARD1 homolog present, except for Medicago truncatula, in which only a BARD1 homolog has been annotated (this homolog was wrongly named "BRCA1"). In Manihot esculenta, we were even able to find two predicted BARD1 genes, and, for Glycine max, we were able to identify two $B R C A 1$ genes. These genes usually had the typical BRCA1/BARD1 structure, although the RING domain seems to be absent in Vitis vinifera BARD1 and in Zea mays BRCA1. It remains to be tested whether these really are functional homologs for both genes. The genome sequence of Carica papaya was also scanned for putative BRCA1 and BARD1 homologs, but the current state of the database did not allow us to get clear results, therefore we excluded the C. papaya sequences from further analysis.

Interesting and unsuspected data were obtained when Chlorophyta, and Lycopodiopsida were checked for BRCA1 and BARD1 homologs: Only one homologous gene was annotated in the spikemoss Selaginella moellendorffii (Lycopodiopsida) and in the green algae Chlamydomonas reinhardtii, Ostreococcus tauri, $O$. lucimarinus, and Volvox carteri (Chlorophyta).

Another very exciting finding was the presence of the PHD domain, which is absent in animal BRCA1 and BARD1 proteins. We were able to find this domain in all tested BRCA1 and BARD1 proteins with the exception of the green algae C. reinhardtii and $V$. carteri. Furthermore, one important cysteine residue was not conserved in the PHDs of the S. moellendorffi, O. tauri, and $O$. lucimarinus proteins (see Figure 2 for an alignment).

Together, these findings prompted us to develop a hypothesis about the evolution of the animal and plant BRCA1 and BARD1 proteins.

\section{A NEW HYPOTHESIS FOR THE EVOLUTION OF BRCA1 HOMOLOGS}

The observation that the plant BRCA1 and BARD1 proteins carry a common domain not present in the animal homologs could hint at the possibility that both arose from a duplication event during the early evolution of the plant kingdom. Thus, AtBRCA1 and AtBARD1 would not be true orthologs of HsBRCA1 and HsBARD1, but rather paralogs with one common BRCA1/BARD1-like ancestor. The recent accumulation of genome sequences made it possible to test our hypothesis. 


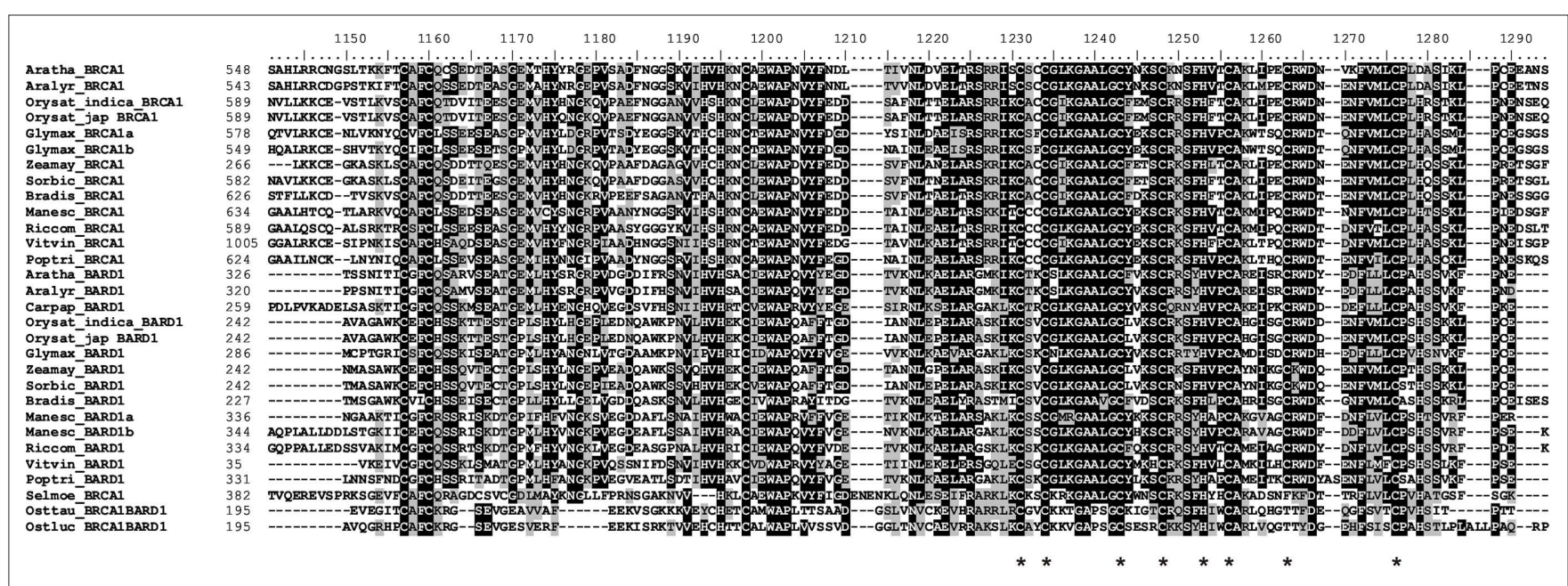

FIGURE 2 |Alignment of the PHD domains and their C-terminal extension. Shown here is an alignment of all the extended PHD domains found in the putative BRCA1 and BARD1 homologs of plants. The C4HC3 motif residues that are typical for PHD fingers are marked with an asterisk. It is clearly visible that the N-terminal area upstream of the typical PHD motif is also highly conserved.
In fact, it is the most highly conserved domain in the plant BRCA1 and BARD1 homologs. The only organisms for which we could not find a PHD were Chlamydomonas reinhardtii and Volvox carteri. The PHD in Selaginella moellendorffii and both Ostreococcus species lack one conserved cysteine in this motif.
Considering the large number of BRCA1 and BARD1 proteins in different organisms and the presence of the PHD domain in almost all sequenced plants, we suggest the following hypothesis concerning the evolution of the BRCA1 and BARD1 proteins (see Figures 3 and 4):

Animal and plant BRCA1 and BARD1 have one common eukaryotic ancestor. However, is this due to a single event or multiple duplication events? Using Occam's razor, the simplest explanation would be that after the separation of the plant and animal kingdoms, a single plant homolog subsequently gained a PHD domain. Independent duplications of the predecessor gene in both kingdoms seem to have occurred later, leading to the mammalian BRCA1 and BARD1 genes that lack PHD domains and the plant BRCA1 and BARD1 genes that harbor PHD domains. The incorporation of the PHD seems to have happened on the evolutionary level of the green algae, about 1150 million years ago (Yoon et al., 2004; Hedges et al., 2006). The duplication in the plant kingdom seems to have happened after the divergence of the Lycopodiopsida and Spermatophytina lineages and earlier than the divergence of monocots and dicots, because we find a BRCA1 and a BARD1 homolog in both of them. This places the duplication between 495.9 and 301 million years ago (Soltis et al., 2002; Hedges et al., 2006; Zimmer et al., 2007).

There are several lines of argument supporting this hypothesis:

(i) The animal BRCA1 and BARD1 proteins do not harbor PHD domains, whereas the PHD domains of the plant BRCA1 and BARD1 proteins are very similar in sequence and position. If there were already two proteins present in the last common ancestor of animals and plants, a possible gain or loss of the PHD after the separation of plants and animals must have happened twice at a similar position in the gene, which is very unlikely.

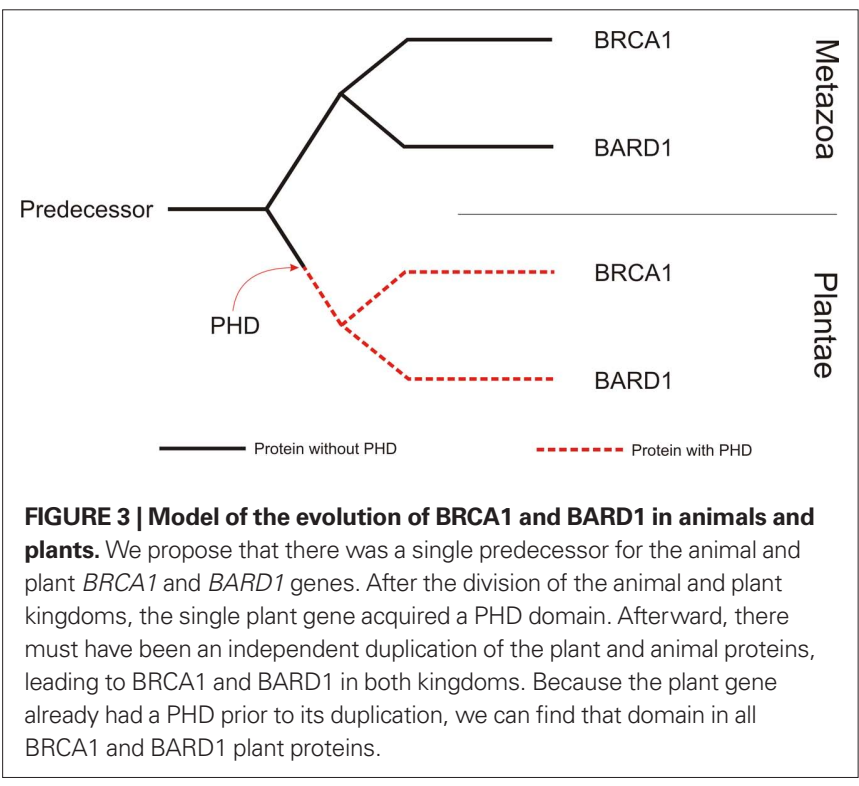

(ii) The green algae genomes analyzed thus far and the genome of the moss S. moellendorffii have only one BRCA1/BARD1 protein. Unfortunately, the sequence data for these species are still very preliminary, and additional BRCA1/BARD1 proteins could exist. Furthermore, $P$. patens has no BRCA1 or BARD1 homolog. A scenario in which Physcomitrella lost one BRCA1/BARD1 is more likely than a scenario in which all green algae and mosses lost one or both of the BRCA1 and BARD1 proteins, which would have been the case if two ancestors had existed.

(iii) No PHD domain could be identified in the BRCA1/ BARD1 predecessor protein in Chlorophyceae (C. reinhardtii and $V$. carteri), but a PHD was found in the 


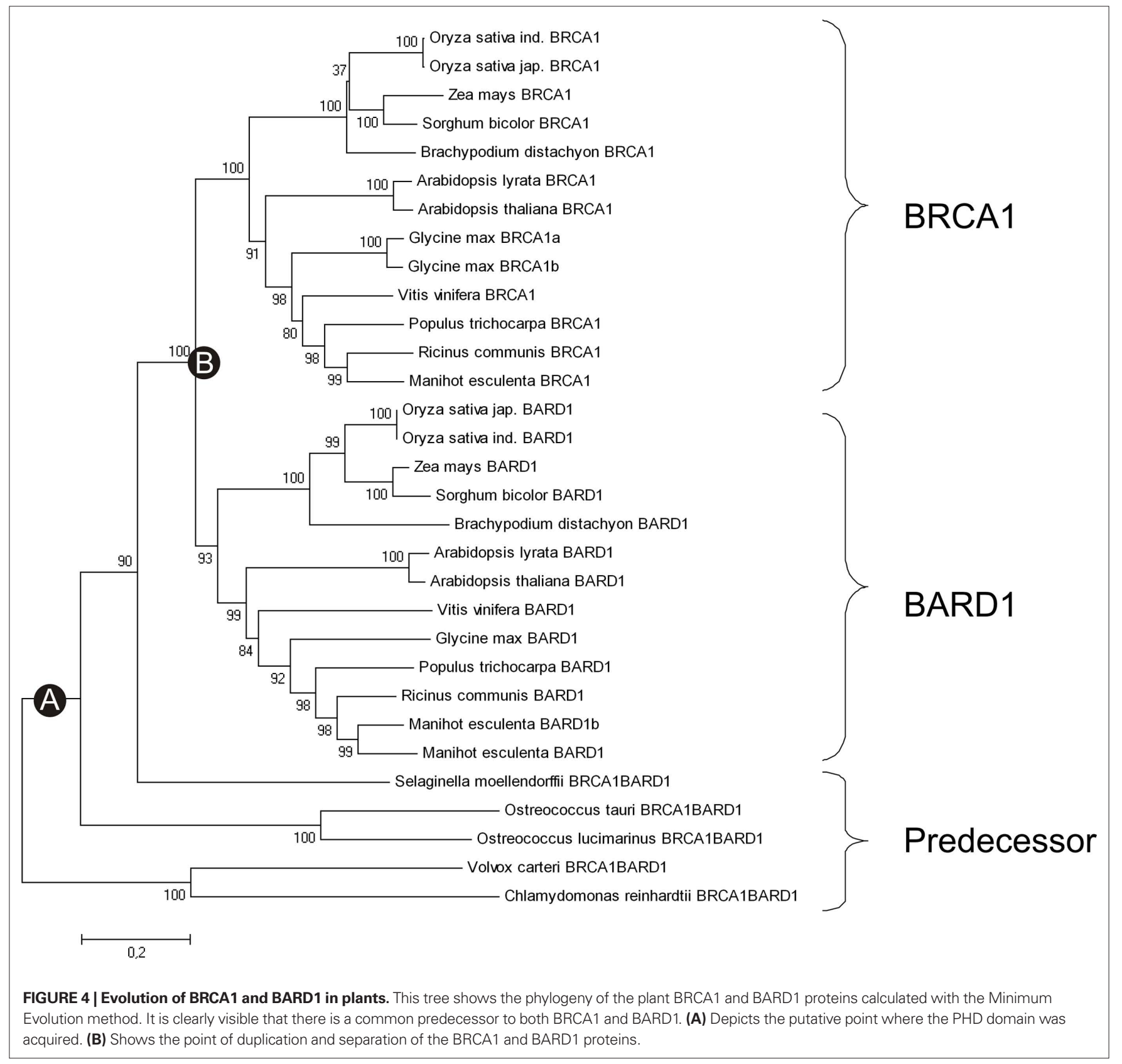

BRCA1/BARD1 homolog of both Ostreococcus species sequenced thus far, which also belong to the green algae. This suggests that the PHD was acquired on the evolutionary level of the green algae before the plant predecessor gene was duplicated. However, because we can find a PHD in Ostreococcus but not in Chlamydomonas and Volvox, we can not rule out the possibility that a PHD was incorporated even earlier and got lost in the Chlorophyceae branch of the green algae.

This leads to another hypothesis that is less likely though. If the plant and animal predecessor protein already possessed a PHD domain, the animal protein must have lost its PHD before duplication. Yet C. reinhardtii and V. carteri would have had to both lose the PHD domain, as well, which makes this "multiple loss of PHD" supposition less probable than the "single gain of PHD" hypothesis.

Unfortunately, BRCA1 or BARD1 proteins in other kingdoms, which would be very helpful for the further elucidation of the evolution of these proteins, could not be identified.

A consequence of the hypothesis of the evolution of BRCA1 and BARD1 described above is that the Arabidopsis BRCA1 and BARD1 genes are not orthologs of the human BRCA1 and BARD1 and that these genes rather developed analogously from a common $B R C A 1 /$ $B A R D 1$ predecessor. Thus, BRCA1- and BARD1-specific features might differ between humans and plants. This makes BRCA1 and BARD1 analysis in plants and animals both more challenging and more fascinating. 


\section{BRCA1 COMPLEXES}

In humans, BRCA1 is the central compound in three distinct complexes that have different functions important for the repair of damaged DNA (Wang et al., 2007; overview in Huen et al., 2010). In every complex, BRCA1 exists as a heterodimer with its interaction partner BARD1, and, apart from these two proteins, all other components differ among the three complexes. The complexes were named the BRCA1 A, B, and C complexes after the bridging proteins that interact with BRCA1's BRCT domains: ABRAXAS1 (ABRA1), BACH1 (FANCJ), and CtIP, respectively. For an overview of the human complexes, see Figure 5. Interestingly, homologs of almost all of the interaction partners in these complexes can be found in the Arabidopsis genome (for a compilation, see Table 1). We were not able to identify homologs of PALB2 (partner and localizer of BRCA2, also known as FANCN), ABRA1 (Abraxas 1), and RAP80 (receptor associated protein 80 ). It is possible that TOPBP1 (topoisomerase II binding protein 1) has a homolog in Arabidopsis called AtMEI1 although this is not yet functionally verified (Grelon et al., 2003). Additionally, we found that, apart from BRCA2, two homologs are duplicated in Arabidopsis, namely BRCC36 and

\section{BRCA1 A complex}

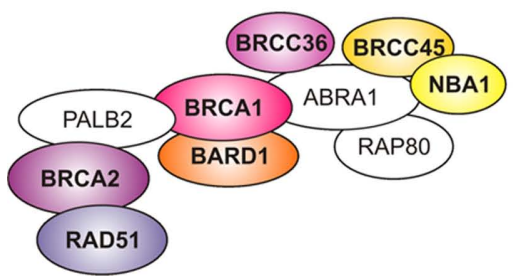

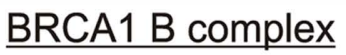

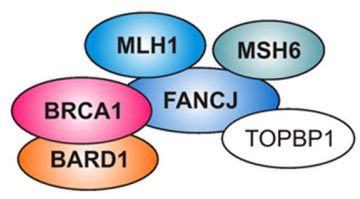

\section{BRCA1 C complex}

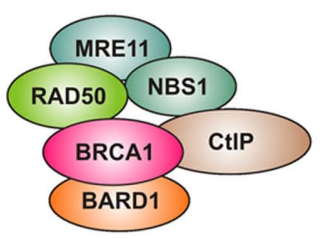

FIGURE 5 |The three BRCA1 complexes in humans. The three human complexes in which the BRCA1-BARD1 heterodimer was found are called the $A, B$, and $C$ complexes. The A complex is involved in DNA repair via homologous recombination. The heterodimer is needed to load RAD51 on single-stranded DNA, where it then catalyzes the strand invasion. The $B$ complex has a role in the $\mathrm{G} 1 / \mathrm{S}$ cell cycle checkpoint, and the $\mathrm{C}$ complex is involved in the G2/M checkpoint and $5^{\prime}$ end resection, which is the initial step after a DNA double strand break. See the text for details. (Proteins with a known homolog in Arabidopsis are colored, and the names are written in bold; ABRA1, Abraxas1;
BARD1, BRCA1 associated RING domain protein 1; BRCA1, breast cancer susceptibility gene 1; BRCA2, breast cancer susceptibility gene 2; BRCC36, BRCA1/BRCA2 containing complex subunit 36; BRCC45, BRCA1/BRCA2 containing complex subunit 45; CtIP, CtBP interaction partner; FANCJ, Fanconi anemia complementation group J; MLH1, mutL Homolog 1; MRE11, meiotic recombination 11 homolog A; MSH6, mutS Homolog 6; NBA1, new component of the BRCA1 A complex; NBS1, Nijmegen breakage syndrome 1; PALB2, partner and localizer of BRCA2; RAD50, radiation sensitive 50; RAD51, radiation sensitive 51 ; TopBP1, topoisomerase 2 binding protein 1)

Table 1 | Proteins of the three human BRCA1 complexes, the BRISC and their homologs in Arabidopsis.

\begin{tabular}{|c|c|c|c|c|}
\hline Protein & Human accession No. & Human length (aa) & Arabidopsis accession No. & Arabidopsis length \\
\hline ABRA1 & NP_620775.2 & 409 & - & - \\
\hline ABRO1 & NP_115558.3 & 415 & NP_187490.2 (splice variant 1) & 313 \\
\hline BARD1 & NP_000456.2 & 777 & NP_973758.2 & 713 \\
\hline BRCA1 & NP_009225.1 (isoform 1) & 1863 & NP_193839.4 & 941 \\
\hline \multirow[t]{2}{*}{ BRCA2 } & NP_000050.2 & 3418 & (IV) NP_001154192.1 & 1187 \\
\hline & & & (V) NP_195783.3 & 1155 \\
\hline \multirow[t]{2}{*}{ BRCC36 } & NP_077308.1 (isoform 1) & 316 & (A) NP_178138.2 & 414 \\
\hline & & & (B) NP_001078118.1 & 405 \\
\hline BRCC45 & NP_004890.2 & 415 & NP_199062.2 & 382 \\
\hline CtIP & NP_002885.1 (isoform a) & 897 & NP_850683.1 & 588 \\
\hline \multirow[t]{2}{*}{ FANCJ } & NP_114432.2 & 1249 & (A) AT1G20750.1 & 1144 \\
\hline & & & (B) NP_173495.5 & 1175 \\
\hline MRE11 & NP_005582.1 (isoform 1) & 708 & NP_200237.1 & 720 \\
\hline NBA1 & NP_001028721.1 & 329 & NP_195022.1 & 264 \\
\hline NBS1 & NP_002476.2 & 754 & NP_186917.2 & 542 \\
\hline PALB2 & NP_078951.2 & 1186 & - & - \\
\hline RAD50 & NP_005723.2 & 1312 & NP_565733.1 & 1316 \\
\hline RAD51 & NP_002866.2 & 339 & NP_568402.1 & 342 \\
\hline RAP80 & NP_057374.3 & 719 & - & - \\
\hline TOPBP1 & NP_008958.2 & 1522 & - & - \\
\hline
\end{tabular}


FANCJ. Duplicated genes occur quite often in Arabidopsis (for example, see Hartung et al., 2007) as there seems to have been a partial genome duplication in the family Brassicaceae.

\section{BRCA1 A COMPLEX}

The BRCA1 A complex is the best-described complex featuring the BRCA1-BARD1 heterodimer. In mammals, this complex was shown to function mainly in HR after DNA damage through its recruitment of the RAD51 protein that is essential for strand invasion (Scully et al., 1997b). In humans, the BRCA1 A complex is probably found in foci near DNA DSBs (Scully et al., 1997b). BRCA1 binds with its BRCT domain to phosphorylated ABRA1, which acts as a scaffold and binds BRCC36 (BRCA1/BRCA2containing complex subunit 36, also known as BRCC3), a deubiquitinating enzyme, BRCC45 (BRCA1/BRCA2-containing complex subunit 45, also known as BRE), and RAP80, which is essential for the recruitment of BRCA1. BRCA1 itself binds to PALB2, which then localizes BRCA2 and RAD51 to the proximity of the damaged DNA, where RAD51 can exercise its important function for HR. The most recently identified factor in this complex is NBA1 (New component of the BRCA1 A complex), also known as MERIT40; it interacts with BRCC45 and is also needed for an optimal A complex foci formation (Feng et al., 2009; Wang et al., 2009). Bioinformatics also revealed that the A complex resembles the lid complex of the $26 \mathrm{~S}$ proteasome, which can cleave ubiquitin (Wang et al., 2009).

Some of the members of this complex could also be found in another closely related cytoplasmic complex called BRISC (BRCC36 containing isopeptidase complex; Cooper et al., 2009). In humans, this protein complex consists of BRCC36, BRCC45, ABRO1 (Abraxas brother 1), and NBA1. The BRISC was shown to deubiquitinate K63-linked ubiquitin chains of unknown substrates in the cytoplasm (Cooper et al., 2009). Homologs of all of its components can be found in the Arabidopsis genome, as well (see Table 1), so it is possible that a similar complex is functional in plants, as well. Most notably, in the moss P. patens, in which BRCA1 or BARD1 is present, all the BRISC factors can also be found. Thus, it is possible that the BRISC complex is more widely conserved than the BRCA1 A complex and has an important function not only in seed plants, but also in more primitive plants.

Two homologs of HsBRCC36 could be identified in Arabidopsis: AtBRCC36A and AtBRCC36B (Block-Schmidt et al., 2010). These genes code for proteins with lengths of 406 and 405 amino acids, respectively. The overall identity between HsBRCC36 and AtBRCC36A is 31.3\%, and between HsBRCC36 and AtBRCC36B, there is $30.1 \%$ identity on the protein level. The two Arabidopsis BRCC36 proteins are $90.9 \%$ identical and were probably duplicated recently. Like the human ortholog, they both harbor an MPN domain, which is the only domain that has been described currently in these proteins. Expression of the two BRCC36 genes was found in all organs, with higher levels in flowers and siliques, a pattern that was similar to the expression patterns of AtBRCA1 and AtBARD1. In contrast to that of AtBRCA1, the transcription of both genes is not significantly induced after $\gamma$-irradiation.

Additionally, a single homolog to HsBRCC36 was found in many other plant species, whereas only Arabidopsis lyrata possesses two BRCC36 genes. As stated above, in P.patens, one BRCC36 homolog was found, although the moss has no BRCA1, BARD1, or BRCA2 homologs. Thus, BRCC36 seems to have functions that are independent of BRCA1, BARD1, and BRCA2 in plants, as well.

To analyze the possible involvement of AtBRCC36A in DNA repair, a localization study was conducted using an AtBRCC36AYFP fusion that was stably transformed into wild-type plants (Block-Schmidt et al., 2010). Surprisingly, the fluorescently tagged construct was detected mainly in the cytoplasm when the plants were grown under standard conditions. After treatment with the DSB-inducing agent bleomycin, the fusion protein was also present in the nucleus. This indicates that BRCC36A moves into the nucleus after DNA damage and probably participates in DNA repair. It is tempting to speculate that the activity of a putative A complex in Arabidopsis might be regulated by this movement. It will be interesting to determine the cellular localization of the other homologs of the A complex (including AtBRCC36B) that are present in plants before and after genotoxic stress treatment.

\section{AN OPEN QUESTION: HOW IS THE BRCA1 A COMPLEX RECRUITED TO DNA DAMAGE IN PLANTS?}

Because the BRCA1 A complex is of utmost importance for the integrity of the genome in mammals, it is also the best-described complex. In humans, the recruitment of BRCA1 to DNA damage is well-characterized and will be briefly described here (see Figure 6).

After recognition of a DSB, the kinases ataxia telangiectasia mutated (ATM) and ataxia telangiectasia and Rad3 related (ATR) phosphorylate many factors needed for DNA repair. One key phosphorylation event is the attachment of a phosphate to the histone variant $\mathrm{H} 2 \mathrm{AX}$ near the DSB, which is then subsequently called $\gamma$-H2AX (Burma et al., 2001). This phosphorylated histone can then be recognized by tri-phosphorylated MDC1 (mediator of DNA-damage checkpoint 1), which itself recruits the ubiquitin E3 ligase RNF8 (RING finger protein 8; Stucki et al., 2005; Huen et al., 2007; Mailand et al., 2007). RNF8 can polyubiquitinate $\gamma$-H2AX with K63-linked ubiquitin with the help of the E2 protein UBC13 (ubiquitin-conjugating enzyme 13), MMS2 (ubiquitin-conjugating enzyme variant MMS2; also known as UEV1, ubiquitin E2 variant 1), and HERC2 (Hect domain and RLD 2). HERC2 probably stabilizes the RNF8-UBC13 interaction (Bekker-Jensen et al., 2010). Additionally, there seems to be a second way to ubiquitinate $\gamma$-H2AX, namely via BMI1, a member of the Polycomb group that was shown to be able to ubiquitinate $\gamma$-H2AX (Ismail et al., 2010). It was recently shown that UBC13 only acts as an E2 protein when the ubiquitin chain gets elongated (Christensen and Klevit, 2009). Therefore, RNF8 might not be involved in the initial monoubiquitination of $\gamma-\mathrm{H} 2 \mathrm{AX}$. It is possible that BMI1 mono-ubiquitinates $\gamma$-H2AX, whereas RNF8 elongates the ubiquitin chain. The next protein in the cascade of recruitment, RNF168 (RING finger protein 168), finds its way to ubiquitinated H2AX with the help of HERC2 and elongates the K63-linked ubiquitin chain further (Doil et al., 2009; Stewart et al., 2009; Bekker-Jensen et al., 2010). K63-linked ubiquitin chains, in contrast to K48-linked ubiquitin chains, do not target the attached protein for degradation but are, among other functions, an important signal for DNA repair. The polyubiquitination via RNF168 also requires UBC13 and MMS2. The ubiquitin chain is then recognized and bound by RAP80 via its ubiquitin interacting motif (UIMs; Kim et al., 2007). RAP80 itself 
interacts with ABRA1, which, in its phosphorylated form, binds to the BRCT domains of BRCA1 (Liu et al., 2007; Wang et al., 2007). Through this interaction, BRCA1 comes to be in proximity to the DSB and can exert its functions in the repair of DNA damage.

Surprisingly, we were not able to detect homologs of several important factors for the recruitment of HsBRCA1 in the Arabidopsis genome. The two RING finger proteins RNF8 and RNF168 are absent, as well as BMI1, HERC2, the ubiquitin chain recognizing RAP80 and the bridging protein ABRA1. Although we cannot exclude the possibility that the sequence conservation is too small to identify these factors in plants by bioinformatics, we favor the hypothesis that these factors are absent in the Arabidopsis genome and also in the genomes of other plants. Either non-related functional homologs exist in plants or the recruitment of the AtBRCA1-AtBARD1 heterodimer might be independent of K63-linked ubiquitin chains. The latter hypothesis raises the question of how AtBRCA1 might be recruited to sites of DNA damage in Arabidopsis. Because BRCA1 acquired a PHD domain during plant evolution, this domain might participate in the recruitment of AtBRCA1 to damaged DNA. This hypothesis is strengthened by the demonstration of the involvement of $\mathrm{H} 3 \mathrm{~K} 4 \mathrm{me} 3$ in genome stability in yeast. This mark can be detected near new DSBs, and it is speculated that it has an important function in making chromatin accessible for an unobstructed DSBR (Faucher and Wellinger, 2010).

\section{BRCA1 B AND C COMPLEXES}

The BRCA1 B complex features Fanconi anemia complementation group J (FANCJ; also known as BACH1 or BRIP1) and TOPBP1 in addition to the central BRCA1/BARD1 heterodimer. Additionally, the mismatch repair proteins mutL homolog 1 (MLH1) and mutS homolog 6 (MSH6) could be coimmunoprecipitated with FANCJ (Greenberg et al., 2006). The B complex is involved in controlling the G1/S cell cycle checkpoint, as well as in removing guanine quadruplex structures and unhooking crosslinks. Thus, it can also pave the way for replication (Yu et al., 2003; Thompson and Hinz, 2009; Gong et al., 2010). MLH1 and MSH6 have already been described in Arabidopsis (Ade et al., 1999; Jean et al., 1999). Additionally, two FANCJ, but no obvious TOPBP1, homologs seem to be present in Arabidopsis (our unpublished data).

The BRCA1 C complex is characterized by the interaction of the BRCA1/BARD1 heterodimer with the protein CtBP interaction partner (CtIP, also known as RBBP8). The other interaction partners in this complex are the members of the MRN complex: MRE11 (meiotic recombination 11 homolog A), RAD50 (radiation sensitive 50 ), and Nijmegen breakage syndrome 1 (NBS1, also known as $\mathrm{NBN}$ ). A role of the C complex in G2/M checkpoint control was proposed first (Yu and Chen, 2004), but recently other functions of the $\mathrm{C}$ complex have been elucidated. It is proposed to be involved in the initial step of HR, namely end resection to form 3' single-strand overhangs, and in the elimination of covalently bound DNA modifications from DSBs (Yun and Hiom, 2009; Nakamura et al., 2010). However, it is also possible that BRCA1 is not involved in $5^{\prime}$ end resection and that this action depends only on CtIP and MRN. The formation of 3' overhangs in humans still needs further investigation to determine which proteins are definitely involved. The MRN complex is highly conserved in Arabidopsis, as well (Bleuyard et al., 2004; Waterworth et al., 2007; Amiard et al., 2010). There is also a homolog of HsCtIP present, which is called AtCOM1 (DaoudalCotterell et al., 2002; Uanschou et al., 2007). The presence of these factors strongly suggest that a BRCA1 C-like complex might be present in Arabidopsis and may exhibit similar functions, such as participation in $5^{\prime}$ end resection. HsCtIP and HsBRCA1 were also shown to have a role in repairing DNA damage that is caused by topoisomerase inhibitors (Nakamura et al., 2010), but it remains to be determined whether the complete $\mathrm{C}$ complex is involved in this reaction and whether the plant homologs are involved in repairing the same kinds of damage.

\section{FURTHER INTERACTION PARTNERS OF BRCA1}

In addition to these complexes, BRCA1 can act together with several other proteins. For example, it was found associated with KU80, an important factor for the NHEJ pathway of DNA-damage repair (Wei et al., 2008). KU80 seems to play a role in the rapid recruitment of BRCA1 to DSBs without exhibiting a direct interaction. This association is a strong sign for BRCA1 also being involved in the NHEJ pathway. Additionally, there have been other reports that suggest a role for BRCA1 in regulating NHEJ together with CHK2 (cell cycle checkpoint kinase 2) and ATM (Wang et al., 2006; Zhuang et al., 2006). Because BRCA1 and KU80 are also present in Arabidopsis (Riha et al., 2002; West et al., 2002; Gallego et al., 2003), it is possible that AtBRCA1 and AtKU80 show a similar functional interaction, but further investigation is needed to address this question.

Another example is the ubiquitination of $\gamma$-tubulin by BRCA1 in humans (Starita et al., 2004), which inhibits the generation of supernumerary centrosomes and explains the involvement of BRCA1 in centrosome duplication. Despite the fact that plants have no centrosomes, $\gamma$-tubulin can be found and is required for microtubule nucleation at microtubule organizing centers in Arabidopsis (Binarova et al., 2006). It is possible that BRCA1-dependent ubiquitination has a role in this process, too. To our knowledge, this question has not been addressed yet in plants.

Apart from these examples there are several other factors known to interact with BRCA1 in mammals. It will be interesting to screen for further AtBRCA1 interaction partners in plants and to determine which of these interactions are conserved between the two kingdoms and whether plant-specific complexes with unique functions can be revealed.

\section{ROLE OF AtBRCA1, AtBARD1, AND AtBRCC36A IN HR AND CROSSLINK REPAIR}

Human BRCA1 is one of the most important factors for genome stability, and it coordinates the DNA-damage response. Mutations in HsBRCA1 impair DNA repair by HR (overview in Huen et al., 2010). Through the application of model recombination substrates (Swoboda et al., 1994) and the use of insertion mutants, Atbrcal mutants (Block-Schmidt et al., 2010), as well as Atbard1 mutants (Reidt et al., 2006), were shown to have defects in HR, which was especially prominent after induction of DSBs by bleomycin.

Recently, the effect of a mutation in AtBRCC36A and At BRCC36B on HR was tested (Block-Schmidt et al., 2010). Surprisingly, only in Atbrcc36a was the HR frequency reduced to a level comparable to those of the Atbrcal and Atbard1 mutants. It was surprising that AtBRCC36B, despite having 90\% identity on the protein level to 
AtBRCC36A, was not involved in HR in Arabidopsis. The Atbrcc36al At $b r c c 36 b$ double mutant behaved like the At $b r c c 36 a$ single mutant, which again shows that AtBRCC36B has no significant effect on HR.

To test for epistasis between Atbrcal and Atbrcc36a, double mutants were established and tested for their HR frequency (Block-Schmidt et al., 2010). The double mutant behaved like the single mutants, which means that there is indeed epistasis between AtBRCA1 and AtBRCC36A. Taking all of the current data into account, it is most likely that the deubiquitinating function of BRCC36 is needed to detach the BRCA1 A complex and the ubiquitin chains from DNA after repair and thus conclude the DNA repair process.

In humans, BRCA1 has a role in meiotic sex chromosome inactivation by silencing sex chromosomes in male meiosis during spermatogenesis (for an overview see Turner, 2007). In plants, studies on the potential role of AtBRCA1 and AtBARD1 in meiosis were conducted as well (Reidt et al., 2006). The amount of viable seeds and pollen was measured in both mutants, and no changes were found compared to wild-type plants. This means that BRCA1 and BARD1 are not essential for meiosis in plants, although possible minor functions could not be excluded by the study.

Also, none of the single BRCC36 T-DNA insertion mutant lines nor the double mutant showed any defects in development or fertility (Block-Schmidt et al., 2010), indicating that AtBRCC36A and AtBRCC36B have no essential role in meiosis, which was also true for AtBRCA1 and AtBARD1.

Mutated $\mathrm{Hs} B R C A 1$ or $\mathrm{Hs} B A R D 1$ genes lead to hypersensitivity against DNA damaging agents like Mitomycin C (MMC), which crosslinks DNA (Westermark et al., 2003). Thus, the BRCA1BARD1 heterodimer seems to be involved directly or indirectly in the repair of crosslinked DNA.

Reidt et al. (2006) showed that both Atbrcal and Atbard1 mutants displayed a mild hypersensitivity after treating the plants with MMC. In contrast, no significantly increased sensitivity was measured after challenging the mutants with UV radiation and the DSB-inducing agent bleomycin. Because the Atbrcal/Atbard1 double mutant did not behave differently from the single mutants, this indicates that both genes are epistatic in DNA crosslink repair in Arabidopsis. Interestingly, both Atbrcc36a and Atbrcc36b exhibit enhanced sensitivity to MMC, like Atbrcal and Atbard1, indicating that BRCC36A and BRCC36B both have a role in crosslink repair, whereas only BRCC36A has a role in HR. Atbrcc36a/Atbrcc36b double mutants show the same sensitivity to MMC as the single mutants, and Atbrcc36a/Atbrcal double mutants show no enhanced sensitivity, compared with the single mutants (Block-Schmidt et al., 2010). Because AtBRCC36B is only involved in crosslink repair, one is tempted to speculate that only AtBRCC36A may be present in a putative BRCA1 A complex.

\section{FUNCTIONS OF AtBARD1 IN TRANSCRIPTIONAL REGULATION}

The BRCA1/BARD1 heterodimer in humans is implicated not only in DNA repair, but also in other processes such as transcriptional regulation (Wu et al., 2008). The fact that BARD1 knockout mice are embryonically lethal further shows that BARD1 is essential for development in mammals (Irminger-Finger and Jefford, 2006). A recent report (Han et al., 2008) demonstrated that AtBARD1 is involved in the transcriptional regulation of
AtWUS (WUSCHEL), which is a protein that controls stem cell fate in the Arabidopsis shoot apical meristem (Laux et al., 1996). Han et al. (2008) discovered that AtBARD1 can suppress AtWUS expression by binding to the AtWUS promoter region and that this protein is crucial for the restriction of AtWUS expression to the organizing center of the shoot apical meristem. Coimmunoprecipitation (CoIP) assays revealed that AtBARD1 interacts with AtSYD (SPLAYED), a SWI-SNF2 ATPase subunit of the chromatin remodeling complex. Therefore, they proposed that AtBARD1 inhibits chromatin remodeling through the PHD domain and that this process is necessary for AtWUS expression (Han et al., 2008; Han and Zhu, 2009).

One of the three Atbard1 mutants that they examined showed no AtBARD1 expression, whereas the other two showed expression of a C-terminal fragment. Only the knockout mutant displayed severe developmental defects with enlarged meristems. This defect could be complemented through the expression of a C-terminal AtBARD1 fragment. Thus, the C-terminal fragment of AtBARD1, which contains the BRCT repeats, appears to be sufficient for the control of AtWUS expression. Surprisingly, an anti-AtBARD1 antibody did not seem to detect full-length AtBARD1 in wildtype extracts but instead gave a signal corresponding only to a C-terminal fragment (Han et al., 2008). Therefore, the authors suggested that only a C-terminal part of AtBARD1 might be present in Arabidopsis plants. This hypothesis seems very unlikely to us because the complete AtBARD1 ORF was conserved during plant evolution. In the "truncated" AtBARD1 protein, the RING domain, which seems to be required for the interaction with AtBRCA1, is absent. The fact that both Atbard1 mutants, which showed expression of a C-terminal mRNA, displayed defects in DNA repair at the same level as the AtBRCA1 mutant (Reidt et al., 2006) demonstrates that the N-terminal fragment of AtBARD1 is indeed essential for DNA repair. Further experiments will be necessary to clarify the matter.

\section{THE BRCA2 PROTEIN}

BRCA2 was first identified in 1995 by Wooster et al. (1995) in a screen for breast cancer high-penetrance germline mutations. Orthologs of BRCA2 could be identified in various species, e.g., mouse, zebrafish, Drosophila, C. elegans and Ustilago maydis, but not in yeast (Sharan and Bradley, 1997; Marston et al., 1999; Kojic et al., 2002; Martin et al., 2005; Titus et al., 2006; Klovstad et al., 2008). Arabidopsis thaliana is the only species known to have two homologs of the BRCA2 gene. Siaud et al. (2004) first described these homologs as a result of a recent duplication that is restricted to the BRCA2 locus. One BRCA2 gene is located in the subtelomeric region of chromosome IV (which was first named $B R C A 2(I V)$ but was referred to as $B R C A 2 A$ in later publications) and the other, on chromosome $\mathrm{V}$ (first named $B R C A 2(V)$, but later referred to as $B R C A 2 B$ ). Both genes share $96.8 \%$ identity, are transcriptionally active and, in contrast to At $B R C A 1$ expression, are not induced by $\gamma$-irradiation. They are expressed in flower buds, but their expression can also be detected in shoot and root apexes and, in the case of BRCA2A, at moderate levels in leaves (Siaud et al., 2004; Wang et al., 2010).

All BRCA2 proteins contain the characteristic BRC motifs in various numbers ranging from 1 in C. elegans and $U$. maydis up to 15 in Trypanosoma (Kojic et al., 2002; Martin et al., 2005; Hartley 
and Mcculloch, 2008). HsBRCA2 is a very large protein consisting of 3418 amino acids harboring 8 BRC repeats (Bork et al., 1996). The AtBRCA2 genes encode for shorter proteins that are 1151 aa (BRCA2A) and 1155 aa (BRCA2B) long; they are 94.5\% identical to each other and 21\% identical to HsBRCA2 (see Figure 7 for a comparison of BRCA2 proteins from human and Arabidopsis). Four BRC repeats could be identified in the AtBRCA2 proteins. Interestingly, BRC2 (BRC motifs were numbered in order of occurrence in the Arabidopsis proteins) is not identical between the two Arabidopsis homologs (Siaud et al., 2004).

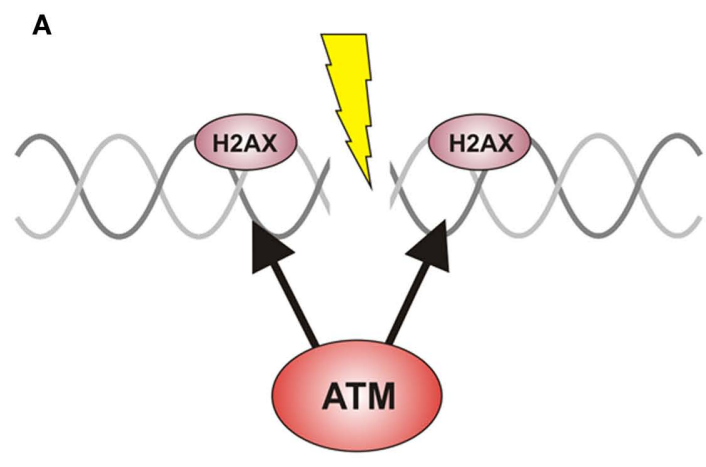

\section{B}
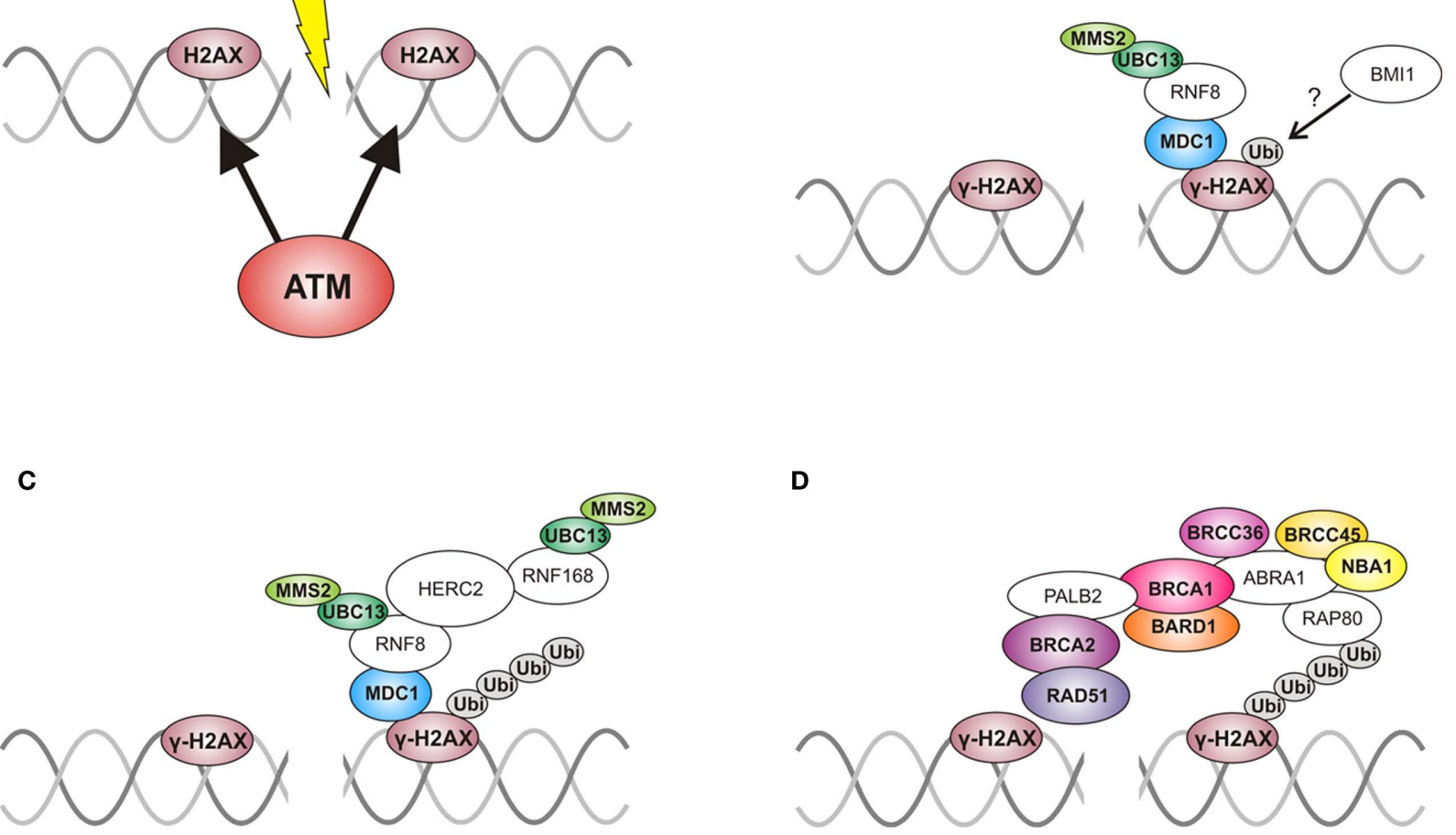

FIGURE 6 | Recruitment of the BRCA1 A complex to a DSB in mammals. (A) After a double strand break (DSB) is recognized, ATM phosphorylates the histone variant $\mathrm{H} 2 \mathrm{AX}$ in proximity to the $\mathrm{DSB}$, which is subsequently called $\gamma-\mathrm{H} 2 \mathrm{AX}$. (B) Next, the mono-ubiquitination of the phosphorylated H2AX occurs. It is unclear which protein facilitates this, but it is possible that RNF8 is responsible for the initial ubiquitination together with the $\mathrm{E} 2$ ligase UBC13 and MMS2. Another hypothesis is that BMI1 mono-ubiquitinates $\gamma-\mathrm{H} 2 \mathrm{AX}$ before RNF8 is recruited, and RNF8 elongates the K63-linked ubiquitin chain. (C) With the help of HERC2, RNF168 is recruited and further elongates the ubiquitin chain, again with UBC13 and MMS2. (D) The ubiquitin chain is then recognized

by RAP80, a part of the BRCA1 A complex. This complex then orchestrates DNA repair by bringing RAD51 to the DSB. (Proteins with a known homolog in Arabidopsis are colored and the names are written in bold; ABRA1, Abraxas; ATM, ataxia telangiectasia mutated; BARD1, BRCA1 associated RING domain protein 1; BRCA1, breast cancer susceptibility gene 1; BRCA2, breast cancer susceptibility gene 2; BRCC36, BRCA1/BRCA2 containing complex subunit 36; BRCC45, BRCA1/BRCA2 containing complex subunit 45; MDC1, mediator of DNA-damage checkpoint protein 1; NBA1, new component of the BRCA1 A complex; PALB2, partner and localizer of BRCA2; RAD51, radiation sensitive 51)

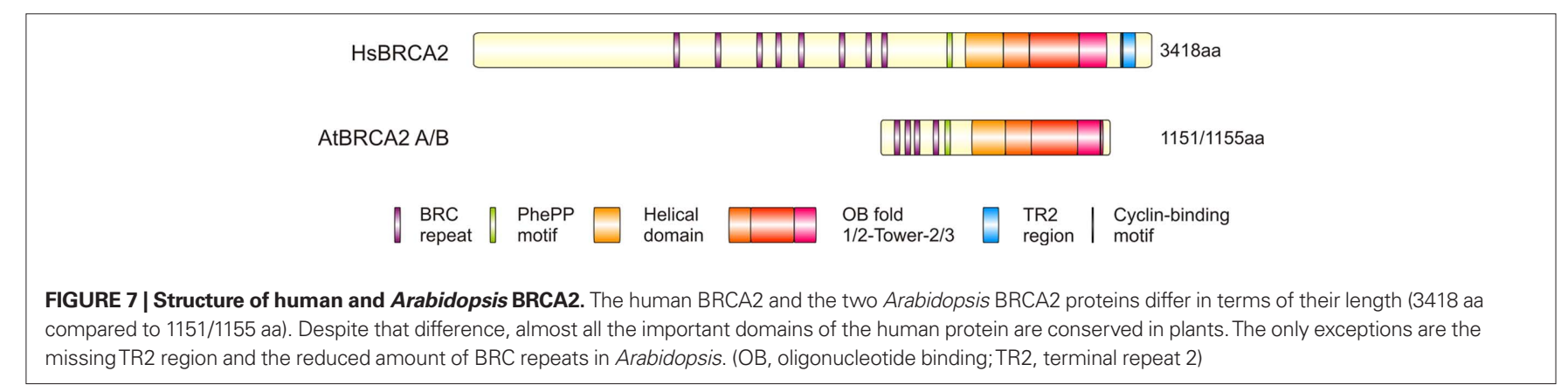


HsBRCA2 interacts with the strand exchange protein HsRAD51 (Chen et al., 1998a, b; Marmorstein et al., 1998) and is crucial for RAD51 foci formation after DNA damage (Sharan et al., 1997; Yuan et al., 1999). Both proteins colocalize in nuclear foci after the treatment of somatic cells with ionizing radiation (IR; Tarsounas et al., 2004). The BRC repeats are important for the interaction with HsRAD51. Multiple yeast two-hybrid and pull-down studies have been conducted to investigate the interaction between HsRAD51 and single BRC motifs or fragments containing more than one BRC repeat (Wong et al., 1997; Chen et al., 1998b, 1999; Thorslund et al., 2007). Another RAD51 interaction site could be mapped in the C-terminus of HsBRCA2, the so-called TR2 region (Mizuta et al., 1997; Sharan et al., 1997; Esashi et al., 2005). In the TR2 region, a cyclin binding motif (CBM) and a CDK phosphorylation site are present (Davies and Pellegrini, 2007). TR2 regions are highly conserved in vertebrates, but they seem to be divergent in other species (Davies and Pellegrini, 2007; Thorslund and West, 2007). It was shown that the TR2 region interacts with multimeric RAD51 and that this interaction is lost if the TR2 region is phosphorylated. CDK-dependent phosphorylation occurs at the late G2 phase of the cell cycle, whereas dephosphorylation occurs in response to IR (Esashi et al., 2005, 2007; Davies and Pellegrini, 2007). This phosphorylation/dephosphorylation mechanism seems to be a regulatory system to block $\mathrm{HR}$ when entering into mitosis, but to activate HR in response to DNA damage. A putative CBM could also be identified for both AtBRCA2 genes, but no CDK phosphorylation site has been described thus far (Wang et al., 2010).

Another highly conserved region in the BRCA2 protein is the DSS1/DNA-binding domain (DBD), which consists of a helical domain (HD), oligonucleotide/oligosaccharide binding folds (OB1, 2, and 3), and a coiled-coil domain (Tower) inserted into OB2. Single-stranded DNA (ssDNA) is bound by the OB2 and OB3 domains (Yang et al., 2002; Kojic et al., 2003). The HD and OB1 domains bind DSS1, a protein originally identified as a candidate gene for split hand/split foot syndrome, which has been reported to be involved in many cellular processes besides DNA repair, including development, and protein degradation (Crackower et al., 1996; Krogan et al., 2004). The AtBRCA2 proteins are also predicted to have a DBD homologous to that identified for the human BRCA2 (Kojic et al., 2003; Siaud et al., 2004). Recently, it was shown that purified full-length HsBRCA2 mediates RAD51 filament formation and strand exchange after DNA damage by promoting the assembly of RAD51 onto RPA-coated ssDNA (Jensen et al., 2010; Liu et al., 2010; Thorslund et al., 2010). BRCA2-promoted RAD51 loading is further stimulated by the BRCA2 interacting protein DSS1 (Liu et al., 2010). Therefore, BRCA2 is a key mediator of DNA repair via HR.

HsBRCA2 is also reported to interact with HsDMC1, a meiosisspecific paralog of RAD51 (Thorslund et al., 2007). The primary interaction site could be mapped in front of the DBD and was called the PhePP motif. An interaction of DMC1 with the TR2 region could be detected, but it was shown to be much weaker compared to the interaction of RAD51 with the TR2 region. This former interaction is not influenced by the phosphorylation status of TR2.. A putative PhePP motif could also be identified for the Arabidopsis BRCA2 genes located in between the BRC repeats and the DBD (Thorslund and West, 2007).
Bioinformatics analysis was conducted to identify putative BRCA2 homologs in other plant species. Homologs can be found in many Viridiplantae species, including the green algae C. reinhardtii, $V$. carteri, and O. tauri, as well as all angiosperm genomes released thus far. For some species, more than one BRCA2 is annotated. However, closer examination of the gene order and the predicted domain structures revealed that the tandem duplications always seem to consist of only one gene in which the N-terminal and C-terminal regions are annotated separately. For S. moellendorffii, no BRCA2 homolog has been annotated, but a BLAST search led to a putative $B R C A 2$ homolog. Interestingly, no $B R C A 2$ homolog could be identified for P. patens, which reflects the situation for BRCA1 and BARD1 (our own unpublished results). To date, no data are published for any plant BRCA2 homolog besides the research conducted with the Arabidopsis BRCA2 proteins, and in the following, we will summarize the current state of knowledge. Surprisingly, in addition to evolutionarily conserved functions in DNA repair and recombination, a function of AtBRCA2 in a plant defense mechanism, systemic acquired resistance (SAR), was revealed recently.

\section{INTERACTION STUDIES WITH ARABIDOPSIS BRCA2 PROTEINS}

Y2H studies demonstrated an interaction of both AtBRCA2 proteins with AtRAD51 and AtDMC1, but not with other AtRAD51 homologs (Siaud et al., 2004). These interactions were further confirmed by CoIP studies (Dray et al., 2006). For both complexes, interaction sites could be mapped to the $\mathrm{N}$-terminal regions of the AtBRCA2 proteins. In contrast to mammalian BRCA2, the BRC repeats therefore seem to be the main binding sites for AtRAD51, and no additional RAD51 binding site in the C-terminal region of AtBRCA2 could be detected. Because the N-terminal fragments of BRCA2 used for CoIP contained the BRC repeats and the putative PhePP motif, a DMC1 interaction with the PhePP motif cannot be excluded, and further experiments are needed. Further $\mathrm{Y} 2 \mathrm{H}$ studies with fragments containing one or more BRC repeats of AtBRCA2A or AtBRCA2B defined BRC2 of BRCA2A as the minimum sufficient domain for the interaction with AtDMC1, and BRC4 for the interaction with AtRAD51 (Dray et al., 2006). Interestingly, a BRC3-BRC4 fragment, but not BRC3 or BRC4 alone, also interacts with AtDMC1, indicating that the combination of BRC repeats alters their abilities to bind complex partners, which is also known from interaction studies with HsBRCA2 fragments (see above). A fragment containing all four BRC repeats of AtBRCA2A even interacted with human RAD51 and DMC1 in Y2H studies. Differences between AtBRCA2A and AtBRCA2B are described for the interaction with the Arabidopsis homologs of DSS1, namely DSS1(I) and DSS1(V) (Dray et al., 2006). AtBRCA2B interacted in Y2H and CoIP studies with both DSS1 homologs, whereas AtBRCA2A only seemed to interact with DSS1(I). Interactions could be mapped to the C-terminal part of the proteins, where the DDB is located, which resembles the case in HsBRCA2. CoIP studies further revealed the existence of a tripartite complex consisting of AtBRCA2B, AtDSS1(I) and AtRAD51 or AtDMC1, in which both other complex partners are bound to AtBRCA2B and do not seem to interact directly with each other (Dray et al., 2006). Recently, the presence of the AtBRCA2A-AtRAD51 complex could be demonstrated in planta (Wang et al., 2010). 


\section{FUNCTIONS OF AtBRCA2 IN SOMATIC DNA REPAIR}

The loss of BRCA2 in mice is embryonically lethal, and BRCA2defect mouse and human cells show genomic instability with accumulation of chromosome breaks and radial chromosomes (Suzuki et al., 1997; Patel et al., 1998; Yu et al., 2000; Moynahan et al., 2001; Tutt et al., 2001). The loss of BRCA2 impairs HR-mediated DSBR, resulting in the use of error-prone mechanisms, such as NHEJ (Xia et al., 2001). To investigate the somatic functions of the AtBRCA2 protein, Abe et al. (2009) used transposon insertion mutants found by searching the Ds mutant collection (Nossen background) established by the RIKEN Institute. Both single mutants showed hypersensitivity against the DNA crosslinking agent cisplatin and against $\gamma$-irradiation, whereas the double mutant showed an additive increase in sensitivity, compared with that in the single mutants. Double mutants heterozygous for one of the two BRCA2 genes showed the same phenotype after cisplatin treatment as the corresponding single mutants, leading to the conclusion that the single mutants are recessive mutants. Therefore, both AtBRCA2A and AtBRCA2B seem to be involved in DSBR in somatic cells. Additional studies with Atbrca2 mutants of the cultivar Columbia were conducted recently, albeit with a slightly different outcome (Wang et al., 2010). An Atbrca2a mutant was identified in a population generated by fast neutron mutagenesis. The Atbrca2b mutant used was a T-DNA insertion mutant of the SALK collection. Interestingly, only the Atbrca2a mutant was hypersensitive against the crosslinking agent mitomycin C and the DSB-inducing agent bleomycin (Wang et al., 2010). Moreover, only the Atbrca2a mutant showed a defect in somatic HR. Thus, depending on the cultivar used in the respective study, there seemed to be redundant and distinct roles for BRCA2A and BRCA2B in DSBR, which could have been caused by the sequence variation in the BRC2 repeats. However, differences in the expression patterns cannot be excluded. Furthermore, it is possible that not all mutants used in the studies were complete knockouts. In the case of HR, a $b r c a 2 a / b$ double mutant should be examined to exclude a role for AtBRCA2B in this repair pathway. Thus, Arabidopsis BRCA2 proteins seem to have a role in DSBR, especially in HR, that is similar to that of mammalian BRCA2, but their absence does not lead to embryonic lethality. This difference in viability between mammals and plants is also found in many other Arabidopsis DNA repair proteins for which mutants develop normally to adult stage but then show partial or full sterility, e.g., RAD51C, XRCC3 and RAD50 (Gallego et al., 2001; Bleuyard et al., 2004; Abe et al., 2005).

\section{FUNCTIONS OF AtBRCA2 IN MEIOSIS}

In meiosis, the correct pairing and segregation of homologous chromosomes requires the formation and repair of DNA DSBs (for review, see Inagaki et al., 2010). Expression analysis of mouse BRCA2 first pointed to an involvement for this protein in meiosis. It is highly expressed during spermatogenesis and was detected in early meiotic prophase I (Connor et al., 1997; Blackshear et al., 1998; Chen et al., 1998a). It is difficult to analyze the role of BRCA2 in meiosis in mammals because inactivating this protein leads to embryonic lethality. However, mice expressing a truncated BRCA2 showed a failure in spermatogenesis (Connor et al., 1997), and the rescue of brca2 knockout mice by expressing human BRCA2 resulted in viable, but infertile, mice (Sharan et al., 2004).
In BRCA2-deficient spermatocytes, DSB formation occurs, but recombination fails to be completed and spermatocytes do not progress beyond early stages of prophase I. In these cells, no RAD51 and DMC1 foci could be detected. Therefore, BRCA2 seems to be required for the correct localization of both recombinases to DSBs (Sharan et al., 2004). These results were further sustained by the examination of viable, but sterile, rats expressing a truncated BRCA2 protein. During spermatogenesis, homologous chromosomes failed to synapse, and meiosis did not progress beyond late zygotene (Cotroneo et al., 2007). The BRCA2 homologs of $U$. maydis and C. elegans have also been shown to be essential for meiosis (Kojic et al., 2002; Martin et al., 2005; Ko et al., 2008). Drosophila BRCA2 has been described as having a dual role in meiosis: in the repair of meiotic DSBs and the efficient activation of the meiotic recombination checkpoint (Klovstad et al., 2008). To examine a potential role of AtBRCA2 in meiosis, Siaud et al. (2004) silenced the expression of both $B R C A 2$ genes during meiosis with RNAi under the control of the AtDMC1 promoter. Silencing of the BRCA2 genes resulted in partial sterility for most of the transformants. Abe et al. (2009) reported that silencing of both BRCA2 genes by RNAi under the control of a constitutive promoter also led to partial sterility. In contrast, the double mutant they generated by crossing corresponding transposon mutants of the RIKEN collection showed an overall fertility that was similar to that of the wild-type, although male gamete development was partially defective. Wang et al. (2010), however, reported that the double mutant they generated was sterile. Siaud et al. (2004) investigated meiosis in BRCA2-silenced plants in detail. Silencing of AtBRCA2 led to severe male meiotic phenotypes. DAPI-stained chromosomes in pollen mother cells (PMCs) showed a failure in pairing and synapsis of homologous chromosomes, and no bivalents could be seen after prophase I. Univalents seemed to be entangled and segregated in an uncoordinated manner in anaphase I. Chromatin bridges could be seen between separating chromosomes. In anaphase II, chromatids improperly segregated with elements sometimes being left aside. Meiosis II resulted in the formation of polyads. The brca2 phenotype was dependent on SPO11-induced DSBs because it was eliminated in spo11 mutant plants. These observations indicated that meiotic HR was defective in BRCA2-silenced plants, and chromosomes were improperly connected, which led to fragmentation during separation processes. The coordination of chromosome movement was disturbed, and sister chromatid separation was also affected. This phenotype was similar to the rad51 meiotic phenotype described by Li et al. (2004) and different from the At $d m c 1$ meiotic phenotype described by Couteau et al. (1999). Atrad51 mutant plants were sterile; the PMCs were characterized by univalents, severe chromosome fragmentation, and the formation of polyads instead of tetrads (Li et al., 2004). PMCs of At $d m c 1$ mutant plants displayed random segregation of univalents, but no chromosome fragmentation could be observed. Their residual fertility was $1.5 \%$, compared with that of the wild-type (Couteau et al., 1999). Siaud et al. (2004) also examined the effects of meiotic silencing of DMC1 and RAD51 by RNAi in wild-type and $d m c 1$ mutant backgrounds. Silencing of $D M C 1$ in a wild-type background led to a phenotype comparable to that described for an At $d m c 1$ mutant, but silencing of RAD51 did not result in a meiotic phenotype comparable to the mutant. Interestingly, the silencing 
of RAD51 in a $d m c 1$ mutant background led to a phenotype similar to that caused by BRCA2 silencing. This finding can be taken as indicating a role of the AtBRCA2 proteins in mediating the function of both RAD51 and DMC1 in meiosis, which is similar to what is seen in the mammalian system. However, further experiments are required to define the influence of the BRCA2 proteins on both recombinases in A. thaliana in detail.

\section{FUNCTIONS OF AtBRCA2 IN CELL PROLIFERATION AND CELL CYCLE REGULATION}

Besides HR, BRCA2 has been suggested to be involved in cell cycle regulation (Marmorstein et al., 2001; Kraakman-Van Der Zwet et al., 2002; Lomonosov et al., 2003; Bartek et al., 2004), transcriptional regulation (Milner et al., 1997; Hughes-Davies et al., 2003), cytokinesis (Daniels et al., 2004; Nakanishi et al., 2007), and cell proliferation (Tian et al., 2005). Abe et al. (2009) showed that, occasionally, Atbrca2a/b double mutant plants display increased fasciation and abnormal phyllotaxy and that the rate of plants having these phenotypes could be increased by $\gamma$-irradiation. Defects in DSBR, therefore, seem to lead to disorganization of the shoot apical meristem. By using GUS reporter constructs, these researchers could further detect defects in cell cycle progression in the dividing cells of Atbrca $2 a / b$ double mutants. The effect was exacerbated by treatment with the DNA polymerase inhibitor aphidicolin and was strongly induced by cisplatin. This finding points to a function for BRCA2 in cell proliferation and cell cycle regulation in Arabidopsis.

\section{FUNCTIONS OF ATBRCA2 IN SYSTEMIC ACQUIRED RESISTANCE}

In a pioneering study, AtBRCA2A was recently shown to be important in SAR, an inducible plant immune response (Wang et al., 2010). SAR is induced by salicylic acid (SA) after pathogen attack and leads to broad transcriptional changes and the expression of antimicrobial PR proteins (Durrant and Dong, 2004). The molecular link between SAR and HR was discovered in 2007 by Durrant et al. (2007), who described the genetic interaction of AtSNI1, a transcriptional repressor of PR proteins, and the AtRAD51 paralog AtRAD51D. Wang et al. (2010) identified the Atbrca2a mutation by screening for additional mutants that were genetically linked to Atsnil. By fast neutron mutagenesis in the Atsnil mutant background, they generated mutant plants in which the Atsnil phenotype, including dwarfism and distorted leaves, was suppressed. Analysis of this Atbrca2a mutant revealed that AtBRCA2A is required for SA-induced expression of PR proteins. Interestingly, the effect of the Atbrca2b-mutation in an Atsnil-background was also examined, but there was no effect comparable to that of the Atbrca $2 a$ mutation. Further experiments sustained the surprising finding that only AtBRCA2A, but not AtBRCA2B, is important for

\section{REFERENCES}

Abe, K., Osakabe, K., Ishikawa, Y., Tagiri, A., Yamanouchi, H., Takyuu, T., Yoshioka, T., Ito, T., Kobayashi, M., Shinozaki, K., Ichikawa, H., and Toki, S. (2009). Inefficient double-strand DNA break repair is associated with increased fasciation in Arabidopsis BRCA2 mutants. J. Exp. Bot. 60, 2751-2761.
Abe, K., Osakabe, K., Nakayama, S., Endo, M., Tagiri, A., Todoriki, S., Ichikawa, H., and Toki, S. (2005). Arabidopsis RAD51C gene is important for homologous recombination in meiosis and mitosis. Plant Physiol. 139, 896-908.

Ade, J., Belzile, F., Philippe, H., and Doutriaux, M. P. (1999). Four

plant defense. In HR, BRCA2 delivers RAD51 to DSBs and regulates its DNA binding. Wang et al. (2010) also showed that AtRAD51 is a suppressor of SNI1 and that AtRAD51 expression is SA-inducible. Microarray analysis revealed that AtBRCA2A influences the transcription of key regulators of SAR. AtRAD51 is shown to bind directly to promoters of PR genes, which requires AtBRCA2A, but not AtBRCA2B. These results seem to show a unique function for AtBRCA2A in transcriptional regulation in SAR through its interaction with AtRAD51. The authors therefore suggested that the BRCA2A-RAD51 complex is involved in chromatin remodeling to facilitate transcription, and they further proposed that this complex plays a role in safeguarding against transcription-associated DNA instability. This role could reflect a similarity to the function of the human BRCA2-RAD51 complex in transcriptional regulation and could shed light on the connection between BRCA2 deficiency and the special predisposition to breast and ovarian cancer in humans.

\section{CONCLUSIONS AND PERSPECTIVE}

Since the discovery of the first BRCA gene more than 20 years ago, breast cancer genes have been the focus of many research studies due to the severity of their associated diseases, namely breast and ovarian cancer. After thousands of studies, not only the influences of BRCA1 and BRCA2 on tumor formation, but also their involvement in DNA-damage repair, are partly understood in mammals. In contrast, it might seem at first glance that the research on the plant homologs of the breast cancer proteins is still in its infancy. However, plants are valuable alternative models because, unlike in their respective mammalian mutants, mutations are not embryonically lethal. Surprising new insights have already been achieved, indicating that, during the evolution of the breast cancer genes, some functions were conserved, whereas other specific peculiarities arose. BRCA1 and BARD1 homologs in plants carry a PHD domain with unknown functions, and this domain, which is the most conserved part of the proteins, is absent in mammals. Additionally, a BRCA2 homolog was shown to be involved in pathogen defense in plants. This not only demonstrates that there is more than conservation during breast cancer gene evolution, but it also reveals the need to learn more about the biological role of these genes in plants. With the acquisition of additional, more accurate plant genome sequences, it will also be possible to validate the hypothesis of BRCA1 and BARD1 evolution in plants and animals.

\section{ACKNOWLEDGMENTS}

The authors would like to thank Manfred Focke, Daniela Kobbe, Alexander Knoll, Laura Köhler, and Saskia Riedel for critical reading of the manuscript and the members of the Puchta lab for many insightful discussions. Due to size limitations, we regretfully were not able to cite all the relevant literature.

mismatch repair paralogues coexist in Arabidopsis thaliana: AtMSH2, AtMSH3, AtMSH6-1 and AtMSH6-2. Mol. Gen. Genet. 262, 239-249.

Amiard, S., Charbonnel, C., Allain, E., Depeiges, A., White, C. I., and Gallego, M. E. (2010). Distinct roles of the ATR kinase and the Mre11-Rad50-Nbs1 complex in the maintenance of chromosomal stability in Arabidopsis. Plant Cell 22, 3020-3033.

Ballal, R. D., Saha, T., Fan, S., Haddad, B. R., and Rosen, E. M. (2009). BRCAl localization to the telomere and its loss from the telomere in response to DNA damage. J. Biol. Chem. 284, 36083-36098. 
Bartek, J., Lukas, C., and Lukas, J. (2004). Checking on DNA damage in $S$ phase. Nat. Rev. Mol. Cell Biol. 5, 792-804.

Bekker-Jensen, S., Rendtlew Danielsen, J., Fugger, K., Gromova, I., Nerstedt, A., Bartek, J., Lukas, J., and Mailand, N. (2010). HERC2 coordinates ubiquitindependent assembly of DNA repair factors on damaged chromosomes. Nat. Cell Biol. 12,80-86; sup.pp 81-12.

Bienz, M. (2006). The PHD finger, a nuclear protein-interaction domain. Trends Biochem. Sci. 31, 35-40.

Binarova, P., Cenklova, V., Prochazkova, J., Doskocilova, A., Volc, J., Vrlik, M., and Bogre, L. (2006). Gamma-tubulin is essential for acentrosomal microtubule nucleation and coordination of late mitotic events in Arabidopsis. Plant Cell 18, 1199-1212.

Blackshear, P. E., Goldsworthy, S. M., Foley, J. F., Mcallister, K. A., Bennett, L. M., Collins, N. K., Bunch, D. O., Brown, P., Wiseman, R. W., and Davis, B. J. (1998). Brcal and Brca2 expression patterns in mitotic and meiotic cells of mice. Oncogene 16, 61-68.

Bleuyard, J.Y., Gallego, M. E., and White, C. I. (2004). Meiotic defects in the Arabidopsis rad50 mutant point to conservation of the MRX complex function in early stages of meiotic recombination. Chromosoma 113, 197-203.

Block-Schmidt, A. S., Dukowic-Schulze, S., Wanieck, K., Reidt, W., and Puchta, H. (2010). BRCC36A is epistatic to BRCA1 in DNA crosslink repair and homologous recombination in Arabidopsis thaliana. Nucleic Acids Res. 39, 146-154.

Borde, V., Robine, N., Lin, W., Bonfils, S., Geli, V., and Nicolas, A. (2009). Histone $\mathrm{H} 3$ lysine 4 trimethylation marks meiotic recombination initiation sites. EMBO J. 28, 99-111.

Bork, P., Blomberg, N., and Nilges, M. (1996). Internal repeats in the BRCA2 protein sequence. Nat. Genet. 13, 22-23.

Boulton, S. J. (2006). Cellular functions of the BRCA tumour-suppressor proteins. Biochem. Soc. Trans. 34, 633-645.

Burma, S., Chen, B. P., Murphy, M., Kurimasa, A., and Chen, D. J. (2001). ATM phosphorylates histone H2AX in response to DNA doublestrand breaks. J. Biol. Chem. 276, 42462-42467.

Cantor, S. B., and Xie, J. (2010). Assessing the link between BACH1/FANCJ and MLH1 in DNA crosslink repair. Environ. Mol. Mutagen. 51, 500-507.

Chen, C. F., Chen, P. L., Zhong, Q., Sharp, Z. D., and Lee, W. H. (1999). Expression of BRC repeats in breast cancer cells disrupts the BRCA2Rad51 complex and leads to radiation hypersensitivity and loss of $\mathrm{G}(2) / \mathrm{M}$ checkpoint control. J. Biol. Chem. 274, 32931-32935.

Chen, C. F., Li, S., Chen, Y., Chen, P. L., Sharp, Z. D., and Lee, W. H. (1996). The nuclear localization sequences of the BRCA1 protein interact with the importin-alpha subunit of the nuclear transport signal receptor.J. Biol. Chem. 271, 32863-32868.

Chen, J., Silver, D. P., Walpita, D., Cantor, S. B., Gazdar, A. F., Tomlinson, G., Couch, F. J., Weber, B. L., Ashley, T., Livingston, D. M., and Scully, R. (1998a). Stable interaction between the products of the BRCA1 and BRCA2 tumor suppressor genes in mitotic and meiotic cells. Mol. Cell 2, 317-328.

Chen, P. L., Chen, C. F., Chen, Y., Xiao, J., Sharp, Z. D., and Lee, W. H. (1998b). The BRC repeats in BRCA2 are critical for RAD51 binding and resistance to methyl methanesulfonate treatment. Proc. Natl. Acad. Sci. U.S.A. 95, 5287-5292.

Christensen, D. E., and Klevit, R. E. (2009). Dynamic interactions of proteins in complex networks: identifying the complete set of interacting E2s for functional investigation of E3-dependent protein ubiquitination. FEBS J. 276, 5381-5389.

Connor, F., Smith, A., Wooster, R. Stratton, M., Dixon, A., Campbell, E., Tait, T. M., Freeman, T., and Ashworth, A. (1997). Cloning, chromosomal mapping and expression pattern of the mouse Brca2 gene. Hum. Mol. Genet. 6, 291-300.

Cooper, E. M., Cutcliffe, C., Kristiansen, T. Z., Pandey, A., Pickart, C. M., and Cohen, R.E. (2009). K63-specific deubiquitination by two JAMM/MPN+ complexes: BRISC-associated Brcc36 and proteasomal Poh1. EMBO J. 28, 621-631.

Cotroneo, M. S., Haag, J.D., Zan, Y., Lopez, C. C., Thuwajit, P., Petukhova, G. V., Camerini-Otero, R. D., GendronFitzpatrick, A., Griep, A. E., Murphy, C. J., Dubielzig, R. R., and Gould, M. N. (2007). Characterizing a rat Brca2 knockout model. Oncogene 26, 1626-1635.

Couteau, F., Belzile, F., Horlow, C., Grandjean, O., Vezon, D., and Doutriaux, M. P. (1999). Random chromosome segregation without meiotic arrest in both male and female meiocytes of a dmcl mutant of Arabidopsis. Plant Cell 11, 1623-1634.

Crackower, M. A., Scherer, S. W., Rommens, J. M., Hui, C. C., Poorkaj, P., Soder, S., Cobben, J. M., Hudgins, L., Evans, J. P., and Tsui, L. C. (1996). Characterization of the split hand/split foot malformation locus SHFM1 at 7q21.3-q22.1 and analysis of a can- didate gene for its expression during limb development. Hum. Mol. Genet. 5, 571-579.

Daniels, M. J., Wang, Y., Lee, M., and Venkitaraman,A.R. (2004). Abnorma cytokinesis in cells deficient in the breast cancer susceptibility protein BRCA2. Science 306, 876-879.

Daoudal-Cotterell, S., Gallego, M.E., and White, C. I. (2002). The plant Rad50Mre11 protein complex. FEBS Lett. 516, 164-166.

Davies, O. R., and Pellegrini, L. (2007). Interaction with the BRCA2 C terminus protects RAD51-DNA filaments from disassembly by BRC repeats. Nat. Struct. Mol. Biol. 14, 475-483.

Doil, C., Mailand, N., Bekker-Jensen, S., Menard, P., Larsen, D. H., Pepperkok, R., Ellenberg, J., Panier, S., Durocher, D., Bartek, J., Lukas, J., and Lukas, C. (2009). RNF168 binds and amplifies ubiquitin conjugates on damaged chromosomes to allow accumulation of repair proteins. Cell 136, 435-446.

Dray, E., Siaud, N., Dubois, E., and Doutriaux, M. P. (2006). Interaction between Arabidopsis Brca2 and its partners Rad51, Dmc1, and Dss1. Plant Physiol. 140, 1059-1069.

Durrant, W. E., and Dong, X. (2004) Systemic acquired resistance. Annu. Rev. Phytopathol. 42, 185-209.

Durrant, W. E., Wang, S., and Dong, X. (2007). Arabidopsis SNI1 and RAD51D regulate both gene transcription and DNA recombination during the defense response. Proc. Natl. Acad. Sci. U.S.A. 104 4223-4227.

Esashi, F., Christ, N., Gannon, J., Liu, Y., Hunt, T., Jasin, M., and West, S. C. (2005). CDK-dependent phosphorylation of $\mathrm{BRCA} 2$ as a regulatory mechanism for recombinational repair. Nature 434, 598-604.

Esashi, F., Galkin, V.E., Yu, X., Egelman, E H., and West, S.C. (2007). Stabilization of RAD51 nucleoprotein filaments by the C-terminal region of BRCA2. Nat Struct. Mol. Biol. 14, 468-474.

Fabbro, M., Rodriguez, J. A., Baer, R., and Henderson, B. R. (2002). BARD1 induces BRCA1 intranuclear foci formation by increasing RINGdependent BRCA1 nuclear import and inhibiting BRCA1 nuclear export. J. Biol. Chem. 277, 21315-21324.

Faucher, D., and Wellinger, R. J. (2010) Methylated H3K4, a transcriptionassociated histone modification, is involved in the DNA damage response pathway. PLoS Genet. 6, e1001082. doi: 10.1371/journal.pgen.1001082

Feng, L., Huang, J., and Chen, J. (2009). MERIT40 facilitates BRCA1 localization and DNA damage repair. Genes Dev. 23, 719-728.
Gallego, M. E., Bleuyard, J. Y., DaoudalCotterell, S., Jallut, N., and White, C. I. (2003). Ku80 plays a role in nonhomologous recombination but is not required for T-DNA integration in Arabidopsis. Plant J. 35, 557-565.

Gallego, M. E., Jeanneau, M., Granier, F., Bouchez, D., Bechtold, N., and White, C. I. (2001). Disruption of the Arabidopsis RAD50 gene leads to plant sterility and MMS sensitivity. Plant J. 25, 31-41.

Gong, Z., Kim, J. E., Leung, C. C., Glover, J. N., and Chen, J. (2010). BACH1/ FANCJ acts with TopBP1 and participates early in DNA replication checkpoint control. Mol. Cell 37, 438-446.

Greenberg, R. A., Sobhian, B., Pathania, S., Cantor, S. B., Nakatani, Y., and Livingston, D. M. (2006). Multifactorial contributions to an acute DNA damage response by BRCA1/BARD1-containing complexes. Genes Dev. 20, 34-46.

Grelon, M., Gendrot, G., Vezon, D., and Pelletier, G. (2003). The Arabidopsis MEI1 gene encodes a protein with five BRCT domains that is involved in meiosis-specific DNA repair events independent of SPO11-induced DSBs. Plant J. 35, 465-475.

Hakem, R., De La Pompa, J. L., Sirard, C., Mo, R., Woo, M., Hakem, A., Wakeham, A., Potter, J., Reitmair, A., Billia, F., Firpo, E., Hui, C. C., Roberts, J., Rossant, J., and Mak, T. W. (1996). The tumor suppressor gene Brcal is required for embryonic cellular proliferation in the mouse. Cell 85 , 1009-1023.

Hall, J. M., Lee, M. K., Newman, B., Morrow, J. E., Anderson, L. A., Huey, B., and King, M. C. (1990). Linkage of early-onset familial breast cancer to chromosome 17q21. Science 250 , 1684-1689.

Han, P., Li, Q., and Zhu, Y. X. (2008). Mutation of Arabidopsis BARD1 causes meristem defects by failing to confine WUSCHEL expression to the organizing center. Plant Cell 20, 1482-1493.

Han, P., and Zhu, Y. X. (2009). BARD1 may be renamed ROW1 because it functions mainly as a REPRESSOR OF WUSCHEL1. Plant Signal. Behav. $4,52-54$.

Hartley, C. L., and Mcculloch, R. (2008). Trypanosoma brucei BRCA2 acts in antigenic variation and has undergone a recent expansion in BRC repeat number that is important during homologous recombination. Mol. Microbiol. 68, 1237-1251.

Hartung, F., Suer, S., and Puchta, H. (2007). Two closely related RecQ helicases have antagonistic roles in homologous recombination and 
DNA repair in Arabidopsis thaliana. Proc. Natl. Acad. Sci. U.S.A. 104, 18836-18841.

Hashizume, R., Fukuda, M., Maeda, I., Nishikawa, H., Oyake, D., Yabuki, Y., Ogata, H., and Ohta, T. (2001). The RING heterodimer BRCA1-BARD1 is a ubiquitin ligase inactivated by a breast cancer-derived mutation.J. Biol. Chem. 276, 14537-14540.

Hedges, S. B., Dudley, J., and Kumar, S. (2006). TimeTree: a public knowledgebase of divergence times among organisms. Bioinformatics 22, 2971-2972.

Hu, Y. F., Miyake, T., Ye, Q., and Li, R. (2000). Characterization of a novel trans-activation domain of BRCA1 that functions in concert with the BRCA1 C-terminal (BRCT) domain. J. Biol. Chem. 275, 40910-40915.

Huen, M. S., Grant, R., Manke, I., Minn, K., Yu, X., Yaffe, M. B., and Chen, J. (2007). RNF8 transduces the DNAdamage signal via histone ubiquitylation and checkpoint protein assembly. Cell 131, 901-914.

Huen, M. S., Sy, S. M., and Chen, J. (2010). BRCA1, and its toolbox for the maintenance of genome integrity. Nat. Rev. Mol. Cell Biol. 11, 138-148.

Hughes-Davies, L., Huntsman, D., Ruas, M., Fuks, F., Bye, J., Chin, S. F., Milner, J., Brown, L. A., Hsu, F., Gilks, B., Nielsen, T., Schulzer, M., Chia, S., Ragaz, J., Cahn, A., Linger, L., Ozdag, H., Cattaneo, E., Jordanova, E. S., Schuuring, E., Yu, D. S., Venkitaraman, A., Ponder, B., Doherty, A., Aparicio, S., Bentley, D., Theillet, C., Ponting, C. P., Caldas, C., and Kouzarides, T. (2003). EMSY links the BRCA2 pathway to sporadic breast and ovarian cancer. Cell 115, 523-535.

Inagaki, A., Schoenmakers, S., and Baarends, W. M. (2010). DNA double strand break repair, chromosome synapsis and transcriptional silencing in meiosis. Epigenetics 5, 255-266.

Irminger-Finger, I., and Jefford, C.E. (2006). Is there more to BARD1 than BRCA1? Nat. Rev. Cancer 6, 382-391.

Ismail, I. H., Andrin, C., Mcdonald, D., and Hendzel, M. J. (2010). BMI1mediated histone ubiquitylation promotes DNA double-strand break repair. J. Cell Biol. 191, 45-60.

Jean, M., Pelletier, J., Hilpert, M., Belzile, F., and Kunze, R. (1999). Isolation and characterization of AtMLH1, a MutL homologue from Arabidopsis thaliana. Mol. Gen. Genet. 262, 633-642.

Jensen, R. B., Carreira, A., and Kowalczykowski, S.C. (2010). Purified human BRCA2 stimulates RAD51mediated recombination. Nature 467 , 678-683.

Kee, Y., and D'andrea, A. D. (2010). Expanded roles of the Fanconi ane- mia pathway in preserving genomic stability. Genes Dev. 24, 1680-1694.

Kim, H., Chen, J., and Yu, X. (2007). Ubiquitin-binding protein RAP80 mediates BRCA1-dependent DNA damage response. Science 316, 1202-1205.

Klovstad, M., Abdu, U., and Schupbach, T. (2008). Drosophila brca2 is required for mitotic and meiotic DNA repair and efficient activation of the meiotic recombination checkpoint. PLoS Genet. 4, e31. doi: 10.1371/journal. pgen.0040031

Ko, E., Lee, J., and Lee, H. (2008). Essential role of brc- 2 in chromosome integrity of germ cells in C. elegans. Mol. Cells 26, 590-594.

Kojic, M., Kostrub, C. F., Buchman, A. R., and Holloman, W. K. (2002). BRCA2 homolog required for proficiency in DNA repair, recombination, and genome stability in Ustilago maydis. Mol. Cell 10, 683-691.

Kojic, M., Yang, H., Kostrub, C. F., Pavletich, N. P., and Holloman, W. K. (2003). The BRCA2-interacting protein DSS1 is vital for DNA repair, recombination, and genome stability in Ustilago maydis. Mol. Cell 12, 1043-1049.

Koonin, E. V., Altschul, S. F., and Bork, P. (1996). BRCA1 protein products... Functional motifs. Nat. Genet. 13, 266-268.

Kraakman-Van Der Zwet, M., Overkamp, W. J., Van Lange, R. E., Essers, J., Van Duijn-Goedhart, A., Wiggers, I., Swaminathan, S., Van Buul, P. P., Errami, A., Tan, R. T., Jaspers, N. G., Sharan, S. K., Kanaar, R., and Zdzienicka, M. Z. (2002). Brca2 (XRCC11) deficiency results in radioresistant DNA synthesis and a higher frequency of spontaneous deletions. Mol. Cell. Biol. 22, 669-679.

Krogan, N. J., Lam, M. H., Fillingham, J., Keogh, M. C., Gebbia, M., Li, J., Datta, N., Cagney, G., Buratowski, S., Emili, A., and Greenblatt, J. F. (2004). Proteasome involvement in the repair of DNA double-strand breaks. Mol. Cell 16, 1027-1034.

Lafarge, S., and Montane, M. H. (2003). Characterization of Arabidopsis thaliana ortholog of the human breast cancer susceptibility gene 1: AtBRCA1, strongly induced by gamma rays. Nucleic Acids Res. 31, 1148-1155.

Laux, T., Mayer, K. F., Berger, J., and Jurgens, G. (1996). The WUSCHEL gene is required for shoot and floral meristem integrity in Arabidopsis. Development 122, 87-96.

Li, W., Chen, C., Markmann-Mulisch, U., Timofejeva, L., Schmelzer, E., Ma, H., and Reiss, B. (2004). The Arabidopsis
AtRAD51 gene is dispensable for vegetative development but required for meiosis. Proc. Natl. Acad. Sci. U.S.A. 101, 10596-10601.

Liu, J., Doty, T., Gibson, B., and Heyer, W. D. (2010). Human BRCA2 protein promotes RAD51 filament formation on RPA-covered single-stranded DNA. Nat. Struct. Mol. Biol. 17, 1260-1262.

Liu, Z., Wu, J., and Yu, X. (2007). CCDC98 targets BRCA1 to DNA damage sites. Nat. Struct. Mol. Biol. 14, 716-720.

Lomonosov, M., Anand, S., Sangrithi, M., Davies, R., and Venkitaraman, A. R. (2003). Stabilization of stalled DNA replication forks by the BRCA2 breast cancer susceptibility protein. Genes Dev. 17, 3017-3022.

Lorick, K. L., Jensen, J. P., Fang, S., Ong, A. M., Hatakeyama, S., and Weissman, A. M. (1999). RING fingers mediate ubiquitin-conjugating enzyme (E2)dependent ubiquitination. Proc. Natl. Acad. Sci. U.S.A. 96, 11364-11369.

Mailand, N., Bekker-Jensen, S., Faustrup H., Melander, F., Bartek, J., Lukas, C. and Lukas, J. (2007). RNF8 ubiquitylates histones at DNA double-strand breaks and promotes assembly of repair proteins. Cell 131, 887-900.

Mallery, D. L., Vandenberg, C. J., and Hiom, K. (2002). Activation of the E3 ligase function of the BRCA1/BARD1 complex by polyubiquitin chains. EMBO J. 21, 6755-6762.

Marmorstein, L. Y., Kinev, A. V., Chan, G. K., Bochar, D. A., Beniya, H., Epstein, J. A., Yen, T.J., and Shiekhattar, R. (2001). A human BRCA2 complex containing a structural DNA binding component influences cell cycle progression. Cell 104, 247-257.

Marmorstein, L. Y., Ouchi, T., and Aaronson, S. A. (1998). The BRCA2 gene product functionally interacts with p53 and RAD51. Proc. Natl. Acad. Sci. U.S.A. 95, 13869-13874.

Marston, N. J., Richards, W. J., Hughes, D., Bertwistle, D., Marshall, C. J., and Ashworth, A. (1999). Interaction between the product of the breast cancer susceptibility gene BRCA2 and DSS1, a protein functionally conserved from yeast to mammals. Mol. Cell. Biol. 19, 4633-4642.

Martin, J. S., Winkelmann, N., Petalcorin, M. I., Mcilwraith, M. J., and Boulton, S. J. (2005). RAD-51-dependent and -independent roles of a Caenorhabditis elegans BRCA2-related protein during DNA double-strand break repair. Mol. Cell. Biol. 25, 3127-3139.

Meza, J. E., Brzovic, P. S., King, M. C., and Klevit, R. E. (1999). Mapping the functional domains of BRCA1. Interaction of the ring finger domains of BRCA1 and BARD1. J. Biol. Chem. 274, 5659-5665.
Miki, Y., Swensen, J., Shattuck-Eidens, D., Futreal, P.A., Harshman, K., Tavtigian, S., Liu, Q., Cochran, C., Bennett, L. M. Ding, W., Bell, R., Rosenthal, J., Hussey, C., Tran, T., Mcclure, M., Frye, C., Hattier, T., Phelps, R., Haugen-Strano, A., Katcher, H., Yakumo, K., Gholami, Z., Shaffer, D., Stone, S., Bayer, S., Wray, C., Bogden, R., Dayananth, P., Ward, J., Tonin, P., Narod, S., Bristow, P. K. Norris, F. H., Helvering, L., Morrison, P., Rosteck, P., Lai, M., Barrett, J. C., Lewis, C., Neuhausen, S., CannonAlbright, L., Goldgar, D., Wiseman, R., Kamb, A., and Skolnick, M. H. (1994). A strong candidate for the breast and ovarian cancer susceptibility gene BRCA1. Science 266, 66-71.

Milner, J., Ponder, B., Hughes-Davies, L., Seltmann, M., and Kouzarides, T. (1997). Transcriptional activation functions in BRCA2. Nature 386, 772-773.

Mizuta, R., Lasalle, J. M., Cheng, H. L., Shinohara, A., Ogawa, H., Copeland, N., Jenkins, N. A., Lalande, M., and Alt, F.W. (1997). RAB22 and RAB163/ mouse BRCA2: proteins that specifically interact with the RAD51 protein. Proc. Natl. Acad. Sci. U.S.A. 94, 6927-6932.

Morris, J. R., Boutell, C., Keppler, M., Densham, R., Weekes, D., Alamshah, A., Butler, L., Galanty, Y., Pangon, L., Kiuchi, T., Ng, T., and Solomon, E. (2009). The SUMO modification pathway is involved in the BRCA1 response to genotoxic stress. Nature $462,886-890$

Moynahan, M. E., Pierce, A. J., and Jasin, M. (2001). BRCA2 is required for homology-directed repair of chromosomal breaks. Mol. Cell 7, 263-272.

Nakamura, K., Kogame, T., Oshiumi, H., Shinohara, A., Sumitomo, Y., Agama, K., Pommier, Y., Tsutsui, K. M., Tsutsui, K., Hartsuiker, E., Ogi, T., Takeda, S., and Taniguchi, Y. (2010). Collaborative action of Brcal and CtIP in elimination of covalent modifications from double-strand breaks to facilitate subsequent break repair. PLoS Genet. 6, e1000828. doi: 10.1371/ journal.pgen. 1000828

Nakanishi, A., Han, X., Saito, H., Taguchi, K., Ohta, Y., Imajoh-Ohmi, S., and Miki, Y. (2007). Interference with BRCA2, which localizes to the centrosome during $\mathrm{S}$ and early $\mathrm{M}$ phase, leads to abnormal nuclear division. Biochem. Biophys. Res. Commun. 355, 34-40.

O'donovan, P. J., and Livingston, D. M. (2010). BRCA1 and BRCA2: breast/ovarian cancer susceptibility gene products and participants in DNA double-strand break repair. Carcinogenesis 31, 961-967. 
Patel, K. J., Yu, V. P., Lee, H., Corcoran, A., Thistlethwaite, F. C., Evans, M. J., Colledge, W. H., Friedman, L. S., Ponder, B. A., and Venkitaraman, A. R. (1998). Involvement of Brca2 in DNA repair. Mol. Cell 1, 347-357.

Reidt, W., Wurz, R., Wanieck, K., Chu, H. H., and Puchta, H. (2006). A homologue of the breast cancer-associated gene BARD1 is involved in DNA repair in plants. EMBO J. 25, 4326-4337.

Riha, K., Watson, J. M., Parkey, J., and Shippen,D.E. (2002). Telomere length deregulation and enhanced sensitivity to genotoxic stress in Arabidopsis mutants deficient in Ku70. EMBO J. 21, 2819-2826.

Santos-Rosa, H., Schneider, R., Bannister, A. J., Sherriff, J., Bernstein, B.E., Emre, N. C., Schreiber, S. L., Mellor, J., and Kouzarides, T. (2002). Active genes are tri-methylated at $\mathrm{K} 4$ of histone H3. Nature 419, 407-411.

Scully, R., Anderson, S. F., Chao, D.M., Wei, W., Ye, L., Young, R. A., Livingston, D. M., and Parvin, J.D. (1997a). BRCA1 is a component of the RNA polymerase II holoenzyme. Proc. Natl. Acad. Sci. U.S.A. 94, 5605-5610.

Scully, R., Chen, J., Plug, A., Xiao, Y., Weaver, D., Feunteun, J., Ashley, T., and Livingston, D. M. (1997b). Association of BRCA1 with Rad51 in mitotic and meiotic cells. Cell 88, 265-275.

Sharan, S. K., and Bradley, A. (1997). Murine Brca2: sequence, map position, and expression pattern. Genomics 40, 234-241.

Sharan, S. K., Morimatsu, M.,Albrecht, U., Lim, D. S., Regel, E., Dinh, C., Sands, A., Eichele, G., Hasty, P., and Bradley, A. (1997). Embryonic lethality and radiation hypersensitivity mediated by Rad51 in mice lacking Brca2. Nature 386, 804-810.

Sharan, S. K., Pyle, A., Coppola, V., Babus, J., Swaminathan, S., Benedict, J., Swing, D., Martin, B. K., Tessarollo, L., Evans, J. P., Flaws, J. A., and Handel, M. A. (2004). BRCA2 deficiency in mice leads to meiotic impairment and infertility. Development 131, 131-142.

Siaud, N., Dray, E., Gy, I., Gerard, E., Takvorian, N., and Doutriaux, M. P. (2004). Brca2 is involved in meiosis in Arabidopsis thaliana as suggested by its interaction with Dmcl. EMBO J. 23, 1392-1401.

Simons, A. M., Horwitz, A. A., Starita, L. M., Griffin, K., Williams, R. S., Glover, J. N., and Parvin, J. D. (2006). BRCA1 DNA-binding activity is stimulated by BARD1. Cancer Res. 66, 2012-2018.

Soltis, P. S., Soltis, D. E., Savolainen, V., Crane, P. R., and Barraclough, T. G. (2002). Rate heterogeneity among lineages of tracheophytes: integration of molecular and fossil data and evidence for molecular living fossils. Proc. Natl. Acad. Sci. U.S.A. 99, 4430-4435.

Starita, L. M., Horwitz, A. A., Keogh, M.C., Ishioka, C., Parvin, J. D., and Chiba, N. (2005). BRCA1/BARD1 ubiquitinate phosphorylated RNA polymerase II.J. Biol. Chem. 280, 24498-24505.

Starita, L. M., Machida, Y., Sankaran, S., Elias, J. E., Griffin, K., Schlegel, B. P., Gygi, S. P., and Parvin, J. D. (2004). BRCA1-dependent ubiquitination of gamma-tubulin regulates centrosome number.Mol. Cell. Biol. 24, 8457-8466.

Starita, L. M., and Parvin, J. D. (2006). Substrates of the BRCA1-dependent ubiquitin ligase. Cancer Biol. Ther. 5, 137-141.

Stewart, G. S., Panier, S., Townsend, K., Al-Hakim, A. K., Kolas, N. K., Miller, E. S., Nakada, S., Ylanko, J., Olivarius, S., Mendez, M., Oldreive, C., Wildenhain, J., Tagliaferro, A., Pelletier, L., Taubenheim, N., Durandy, A., Byrd, P. J., Stankovic, T., Taylor, A. M., and Durocher, D. (2009). The RIDDLE syndrome protein mediates a ubiquitin-dependent signaling cascade at sites of DNA damage. Cell 136, 420-434.

Stucki, M., Clapperton, J.A., Mohammad, D., Yaffe, M. B., Smerdon, S. J., and Jackson, S. P. (2005). MDC1 directly binds phosphorylated histone $\mathrm{H} 2 \mathrm{AX}$ to regulate cellular responses to DNA double-strand breaks. Cell 123 1213-1226.

Suzuki, A., De La Pompa, J. L., Hakem, R., Elia, A., Yoshida, R., Mo, R., Nishina, H., Chuang, T., Wakeham, A., Itie, A., Koo, W., Billia, P., Ho, A., Fukumoto, M., Hui, C. C., and Mak, T. W. (1997). $\mathrm{Brca} 2$ is required for embryonic cellular proliferation in the mouse. Genes Dev. 11, 1242-1252.

Swoboda, P., Gal, S., Hohn, B., and Puchta, H. (1994). Intrachromosomal homologous recombination in whole plants. EMBO J. 13, 484-489.

Tarsounas, M., Davies, A. A., and West, S. C. (2004). RAD51 localization and activation following DNA damage. Philos. Trans. R. Soc. Lond. B Biol. Sci. 359, 87-93.

Thompson, L. H., and Hinz, J. M. (2009). Cellular and molecular consequences of defective Fanconi anemia proteins in replication-coupled DNA repair: mechanistic insights. Mutat. Res. 668 , 54-72.

Thompson, M.E. (2010). BRCA1 16 years later: nuclear import and export processes. FEBS J. 277, 3072-3078.

Thorslund, T., Esashi, F., and West, S. C. (2007). Interactions between human BRCA2 protein and the meiosis-specific recombinase DMC1.EMBOJ.26, 2915-2922.

Thorslund, T., Mcilwraith, M. J., Compton, S. A., Lekomtsev, S.,
Petronczki, M., Griffith, J. D., and West, S. C. (2010). The breast cancer tumor suppressor BRCA2 promotes the specific targeting of RAD51 to single-stranded DNA. Nat. Struct. Mol. Biol. 17, 1263-1265.

Thorslund, T., and West, S. C. (2007). BRCA2: a universal recombinase regulator. Oncogene 26, 7720-7730.

Tian, X. X., Rai, D., Li, J., Zou, C., Bai, Y., Wazer, D., Band, V., and Gao, Q. (2005). BRCA2 suppresses cell proliferation via stabilizing MAGE-D1. Cancer Res. 65, 4747-4753.

Tischkowitz, M., and Xia, B. (2010). PALB2/FANCN: recombining cancer and Fanconi anemia. Cancer Res. 70 7353-7359.

Titus, T. A., Selvig, D. R., Qin, B., Wilson, C., Starks, A. M., Roe, B. A., and Postlethwait, J.H. (2006). The Fanconi anemia gene network is conserved from zebrafish to human. Gene 371 211-223.

Turner, J. M. (2007). Meiotic sex chromosome inactivation. Development 134 , 1823-1831.

Tutt, A., Bertwistle, D., Valentine, J., Gabriel, A., Swift, S., Ross, G., Griffin, C., Thacker, J., and Ashworth, A. (2001). Mutation in Brca2 stimulates error-prone homology-directed repair of DNA double-strand breaks occurring between repeated sequences. EMBO J. 20, 4704-4716.

Uanschou, C., Siwiec, T., Pedrosa-Harand, A., Kerzendorfer, C., Sanchez-Moran, E., Novatchkova, M., Akimcheva, S. Woglar, A., Klein, F., and Schlogelhofer, P. (2007). A novel plant gene essential for meiosis is related to the human CtIP and the yeast COM1/SAE2 gene. EMBO J. 26, 5061-5070.

Wang, B., Hurov, K., Hofmann, K., and Elledge, S. J. (2009). NBA1, a new player in the Brcal A complex, is required for DNA damage resistance and checkpoint control. Genes Dev. 23, 729-739.

Wang, B., Matsuoka, S., Ballif, B. A., Zhang, D., Smogorzewska, A., Gygi, S. P., and Elledge, S. J. (2007). Abraxas and RAP80 form a BRCA1 protein complex required for the DNA damage response. Science 316, 1194-1198.

Wang, H. C., Chou, W. C., Shieh, S.Y., and Shen, C. Y. (2006). Ataxia telangiectasia mutated and checkpoint kinase 2 regulate $\mathrm{BRCA1}$ to promote the fidelity of DNA end-joining. Cancer Res. 66, 1391-1400.

Wang, S., Durrant, W. E., Song, J., Spivey, N. W., and Dong, X. (2010). Arabidopsis BRCA2 and RAD51 proteins are specifically involved in defense gene transcription during plant immune responses. Proc. Natl. Acad. Sci. U.S.A. 107, 22716-22721.
Wang, W. (2007). Emergence of a DNAdamage response network consisting of Fanconi anaemia and BRCA proteins. Nat. Rev. Genet. 8, 735-748.

Waterworth, W.M., Altun, C., Armstrong, S. J., Roberts, N., Dean, P. J., Young, K., Weil, C. F., Bray, C. M., and West, C. E. (2007). NBS1 is involved in DNA repair and plays a synergistic role with ATM in mediating meiotic homologous recombination in plants. Plant J. 52, 41-52.

Wei, L., Lan, L., Hong, Z., Yasui, A., Ishioka, C., and Chiba, N. (2008). Rapid recruitment of BRCA1 to DNA double-strand breaks is dependent on its association with Ku80. Mol. Cell. Biol. 28, 7380-7393.

West, C. E., Waterworth, W. M., Story, G. W., Sunderland, P. A., Jiang, Q., and Bray, C. M. (2002). Disruption of the Arabidopsis AtKu80 gene demonstrates an essential role for AtKu80 protein in efficient repair of DNA double-strand breaks in vivo. Plant J. 31, 517-528.

Westermark, U. K., Reyngold, M., Olshen, A. B., Baer, R., Jasin, M., and Moynahan, M.E. (2003). BARD1 participates with BRCA1 in homologydirected repair of chromosome breaks. Mol. Cell. Biol. 23, 7926-7936.

Williams, R. S., Green, R., and Glover, J. N. (2001). Crystal structure of the BRCT repeat region from the breast cancerassociated protein BRCA1. Nat. Struct. Biol. 8, 838-842.

Williams, R. S., Lee, M. S., Hau, D. D., and Glover, J. N. (2004). Structural basis of phosphopeptide recognition by the BRCT domain of BRCA1. Nat. Struct. Mol. Biol. 11, 519-525.

Wong, A. K., Pero, R., Ormonde, P. A., Tavtigian, S. V., and Bartel, P. L. (1997). RAD51 interacts with the evolutionarily conserved BRC motifs in the human breast cancer susceptibility gene brca2. J. Biol. Chem. 272, 31941-31944.

Wooster, R., Bignell, G., Lancaster, J., Swift, S., Seal, S., Mangion, J., Collins, N., Gregory, S., Gumbs, C., and Micklem, G. (1995). Identification of the breast cancer susceptibility gene BRCA2 Nature 378, 789-792.

Wooster, R., Neuhausen, S.L., Mangion, J., Quirk, Y., Ford, D., Collins, N., Nguyen, K., Seal, S., Tran, T., Averill, D., Fields, P., Marshall, G., Narod, S., Lenoir, G. M., Lynch, H., Feunteun, J., Devilee, P., Cornelisse, C. J., Menko, F. H., Daly, P. A., Ormiston, W., Mcmanus, R., Pye, C., Lewis, C. M., Cannon-Albright, L. A., Peto, J., Ponder, B. A. J., Skolnick, M. H., Easton, D. F., Goldgar, D. E., and Stratton, M. R. (1994). Localization of a breast cancer susceptibility gene, BRCA2, to chromosome 13q12-13. Science 265, 2088-2090. 
Wu, L. C., Wang, Z. W., Tsan, J. T., Spillman, M. A., Phung, A., Xu, X. L., Yang, M. C., Hwang, L. Y., Bowcock, A. M., and Baer, R. (1996). Identification of a RING protein that can interact in vivo with the BRCA1 gene product. Nat. Genet. 14, 430-440.

Wu, W., Koike, A., Takeshita, T., and Ohta, T. (2008). The ubiquitin E3 ligase activity of BRCAl and its biological functions. Cell Div. 3, 1.

Wu-Baer, F., Lagrazon, K., Yuan, W., and Baer, R. (2003). The BRCA1/BARD1 heterodimer assembles polyubiquitin chains through an unconventional linkage involving lysine residue K6 of ubiquitin. J. Biol. Chem. 278, 34743-34746.

Xia, F., Taghian, D. G., Defrank, J. S., Zeng, Z. C., Willers, H., Iliakis, G., and Powell, S. N. (2001). Deficiency of human BRCA2 leads to impaired homologous recombination but maintains normal nonhomologous end joining. Proc. Natl. Acad. Sci. U.S.A. 98, 8644-8649.

Yang, H., Jeffrey, P. D., Miller, J., Kinnucan, E., Sun, Y., Thoma, N.
H., Zheng, N., Chen, P. L., Lee, W. H., and Pavletich, N. P. (2002). BRCA2 function in DNA binding and recombination from a BRCA2DSS1-ssDNA structure. Science 297, 1837-1848.

Yoon, H. S., Hackett, J. D., Ciniglia, C., Pinto, G., and Bhattacharya, D. (2004). A molecular timeline for the origin of photosynthetic eukaryotes. Mol. Biol. Evol. 21, 809-818.

Yu, V. P., Koehler, M., Steinlein, C., Schmid, M., Hanakahi, L.A., Van Gool, A. J., West, S. C., and Venkitaraman, A. R. (2000). Gross chromosomal rearrangements and genetic exchange between nonhomologous chromosomes following BRCA2 inactivation. Genes Dev. 14, 1400-1406.

Yu, X., and Chen, J. (2004). DNA damageinduced cell cycle checkpoint control requires CtIP, a phosphorylationdependent binding partner of BRCA1 C-terminal domains. Mol. Cell. Biol. 24, 9478-9486.

Yu, X., Chini, C. C., He, M., Mer, G., and Chen, J. (2003). The BRCT domain is a phospho-protein binding domain. Science 302, 639-642.

Yuan, S. S., Lee, S. Y., Chen, G., Song, M., Tomlinson, G. E., and Lee, E. Y. (1999). BRCA2 is required for ionizing radiation-induced assembly of Rad51 complex in vivo. Cancer Res. 59, 3547-3551.

Yun, M. H., and Hiom, K. (2009). CtIPBRCA1 modulates the choice of DNA double-strand-break repair pathway throughout the cell cycle. Nature 459, 460-463.

Zhuang, J., Zhang, J., Willers, H., Wang, H., Chung, J. H., Van Gent, D. C., Hallahan, D. E., Powell, S. N., and Xia, F. (2006). Checkpoint kinase 2-mediated phosphorylation of BRCA1 regulates the fidelity of nonhomologous end-joining. Cancer Res. 66, 1401-1408.

Zimmer, A., Lang, D., Richardt, S., Frank, W., Reski, R., and Rensing, S.A. (2007). Dating the early evolution of plants: detection and molecular clock analyses of orthologs. Mol. Genet. Genomics 278, 393-402.
Conflict of Interest Statement: The authors declare that the research was conducted in the absence of any commercial or financial relationships that could be construed as a potential conflict of interest.

Received: 14 March 2011; paper pending published: 17 April 2011; accepted: 02 June 2011; published online: 20 June 2011.

Citation: Trapp O, Seeliger Kand Puchta H (2011) Homologs of breast cancer genes in plants. Front. Plant Sci. 2:19. doi: 10.3389/ fpls.2011.00019

This article was submitted to Frontiers in Plant Genetics and Genomics, a specialty of Frontiers in Plant Science.

Copyright (c) 2011 Trapp, Seeliger and Puchta. This is an open-access article subject to a non-exclusive license between the authors and Frontiers Media SA, which permits use, distribution and reproduction in other forums, provided the original authors and source are credited and other Frontiers conditions are complied with. 